\title{
Morphodynamic Evolution of Dredged Sandpits
}

Author(s) :M. González, R. Medina, A. Espejo, J. Tintoré, D. Martin, and A. Orfila

Source: Journal of Coastal Research, Number 263:485-502. 2010.

Published By: Coastal Education and Research Foundation

DOI: http://dx.doi.org/10.2112/08-1034.1

URL: http://www.bioone.org/doi/full/10.2112/08-1034.1

BioOne (www.bioone.org) is a nonprofit, online aggregation of core research in the biological, ecological, and environmental sciences. BioOne provides a sustainable online platform for over 170 journals and books published by nonprofit societies, associations, museums, institutions, and presses.

Your use of this PDF, the BioOne Web site, and all posted and associated content indicates your acceptance of BioOne's Terms of Use, available at www.bioone.org/page/terms_of_use.

Usage of BioOne content is strictly limited to personal, educational, and non-commercial use. Commercial inquiries or rights and permissions requests should be directed to the individual publisher as copyright holder. 


\title{
Morphodynamic Evolution of Dredged Sandpits
}

\author{
M. González ${ }^{\dagger}$, R. Medina ${ }^{\dagger}$, A. Espejo ${ }^{\dagger}$, J. Tintoré ${ }^{\ddagger}$, D. Martin $^{\S}$, and A. Orfila \\ †nstituto de Hidráulica Ambiental (IH) \\ Instituto Mediterráneo de Estudios \\ Avanzados \\ Universidad de Cantabria \\ E.T.S. Ingenieros de Caminos \\ IMEDEA (CSIC-UIB) \\ C. y P., Av. de los Castros \\ Mallorca, Spain \\ ${ }^{s}$ Centre d'Estudis
Avançats de Blanes
CEAB (CSIC)
Blanes, Spain
}

s/n 39005 Santander, Spain

gonzalere@unican.es

\begin{abstract}
GONZÁLEZ, M.; MEDINA, R.; ESPEJO, A.; TINTORÉ, J.; MARTIN, D., and ORFILA, A., 2010. Morphodynamic evolution of offshore dredged sandpits. Journal of Coastal Research, 26(3), 485-502. West Palm Beach (Florida), ISSN 0749-0208.

Numerical modeling of dredged pits is conducted to investigate the hydrodynamic and morphodynamic interaction in offshore sand extractions. Based on an analytical formulation, a semianalytical numerical model (MEMPITS) has been developed to study the morphodynamic evolution of offshore $\left(h_{o}>20 \mathrm{~m}\right)$ sand borrow areas. The numerical model has been applied to study the morphodynamic evolution of two offshore sand borrow areas in the Balearic Islands (Spain). Field data allowed a detailed characterization of the evolution of the sandpits. Time series of local hydrodynamics have been obtained using generation models (hindcast) combined with local wave and flow models. A verification of the simple model has been carried out using relatively slight adjustments to the calibration factors. The simple model provides good estimates of the infill rate and migration velocities of the offshore pits on the scale of years. This semianalytical tool allows a quick systematic investigation of the physical mechanisms as well as a detailed sensibility analysis regarding the pit design parameters. These parameters include location (water depth), pit length, width, depth, and orientation with respect to the mean flow. A nondimensional analysis based on the model is also carried out to explore the role of the different variables involved in the evolution of offshore sandpits. Based on the field data and the nondimensional analysis, some basic design recommendations for offshore sandpits are proposed.
\end{abstract}

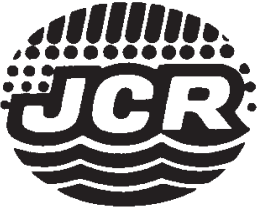

ADDITIONAL INDEX WORDS: Marine mining, offshore marine borrow areas, offshore dredged sandpits, sandpit evolution, sandpit numerical models, sediment transport, Balearic Islands.

\section{INTRODUCTION}

According to the final conclusions of the European Project Sandpit (2005), in many European countries, coastal erosion will require massive mining of sand from the middle and lower shoreface (depths from 10 to $30 \mathrm{~m}$ ). In the European Atlantic Ocean and the Mediterranean Sea, the mining of sand will be required to nourish beaches and coastal dunes in response to increasing coastal erosion because of the expected sea level rise and global warming. Furthermore, given the scale of future demand, sand is needed for large infrastructural projects like artificial islands, ports, airports, as well as for industrial purposes. The present average demand of sand for the European countries is on the order of 3 to 32 million $\mathrm{m}^{3}$ per country and per year; over the next 50 years, it will be on the order of 500 to 3000 million $\mathrm{m}^{3}$ per country (Sandpit, 2005). Eurosion (2004) suggested that every European country should identify and quantify "strategic sediment reservoirs"-defined as the quantity of sediment with "appropriate" characteristics that will be available for future coastal regenerations to compensate for sand lost by storm impacts and also, for coastal protection on long-term scales ( 100 years) because of continued erosion processes.

DOI: 10.2112/08-1034.1 received 29 February 2008; accepted in revision 29 January 2009.
To accomplish the required massive sand mining, countries should explore and exploit new potentially attractive areas. These large scale mining pits may have a significant impact in the near field and far field areas (e.g., biological, ecological, morphological, coastline). To minimize the environmental effects of nearshore coastal erosion, governments will need to situate the mining areas offshore (Sandpit, 2005). This is in contrast to the dredging operating costs, which become progressively more expensive at greater distances from the coast. Therefore, an optimized design requires finding the balance between the minimal coastal impact and the minimal mining costs, a topic that requires more research.

The design of an offshore pit in a marine environment consists of the definition of: (1) the pit location (distance from the coast and water depth) and (2) the pit geometry and orientation (shape, depth, length and width). This means that it is necessary to know the local characteristics such as: (1) bathymetry and sediment characteristics; (2) the local marine dynamics (waves, currents, winds, and sea levels); (3) the likely morphodynamic evolution of the pit once constructed (migration rates, amplitude-decay, and infill time magnitudes); and (4) coastal impacts on shoreline, sediment, and hydrodynamic systems. Reliable tools and local data are required for the design, impact assessment, and maintenance strategies.

Traditionally, the research and morphodynamic model development to study sandpits and trenches have focused on 
the study of nearshore zones: beaches, harbor channels, estuaries, and tidal inlets (Basco, 1999; Basco and Lonza, 1997,; Bender, 2001; Benedet and List, 2008; Demir et al., 2004; Horikawa, Sasaki, and Sakuramoto, 1977; Kelley, Ramsey, and Byrnes, 2004; Simons and Hollingham, 2001; Work, Fehrenbacher, and Voulgaris, 2004). Hence, there is a lack of data, numerical tools, and experience in pits located in offshore areas. To cover this gap, in the frame of the European Project "Sand Transport and Morphology of Offshore Sand Mining Pits" (Sandpit, 2005), research was carried out to better understand the process involved and to develop reliable prediction techniques and guidelines. In the frame of this project, existing morphodynamic models were improved and used to determine the optimum location and dimensions of mining areas. Furthermore, analytical and improved numerical models (one-two dimensional and three dimensional) were calibrated and validated using new and existing data collected from field and laboratory data throughout the project. A detailed description and model performance can be consulted in Van Rijn (2005a, 2005b) and Sandpit (2005).

Large numerical model systems (e.g., Delft2D/3D [Van Rijn, Walstra, and Ormand, 2004]; MIKE 21 CAMS [Hjelmager and Zyserman, 2005]; TELEMAC [Chesher, Soulsby, and Foley, 2005; Chesher et al.,2005b; Davies et al., 2005]) are useful for the simulation of the morphodynamics around specific realistic sandpit designs. However, as expressed in Sandpit (2005) their application is elaborate and time-consuming. Two- and threedimensional (3D) dynamic time series and morphological data are required for these models as input, which are also difficult to acquire. On the other hand, under certain conditions, onedimensional (1D) morphodynamic models have been proposed (Ribberink, 2004; Ribberink, Roos, and Hulsater, 2005; Sandpit, 2005) requiring more simple input data, with an acceptable prediction of the response of offshore sandpits. The basis of the 1D model proposed by Ribberink, Roos, and Hulsater (2005) is formed by a continuity equation for the depth-averaged flow, the sand transport formulation of Bailard (1981) combining waves and currents, and a spatial lag model for suspended sediment (Galappatti and Vreugdenhil, 1985). This 1D model has been previously verified using measured trench evolutions of two laboratory experiments (see Ribberink, 2004). A first rough validation has also been carried out by Ribberink, Roos, and Hulsater (2005) along the Dutch coast (Scheveningen). However, more refined verifications with field cases are still recommended by Ribberink, Roos, and Hulsater (2005). Two offshore borrow areas located in the Balaric Islands (Spain), with some specific characteristics of location (water depths), geometries, and orientation regarding local hydrodynamics, allow the application of a simplified 1D morphodynamic model as that proposed by Ribberink, Roos, and Hulsater (2005) and Ribberink (2004).

The goals of this paper are to analyse the morphodynamic evolution of offshore sandpits based on a semianalytical numerical model developed in this study; to apply the numerical model to study the morphodynamic evolution of the borrow areas of Banyalbufar and Refeubeitx located in the Balearic Islands, which have been dredged several times; to verify the $1 \mathrm{D}$ analytical model proposed by Ribberink, Roos, and Hulsater (2005) using the collected data; and to propose some general recommendations regarding pit design in

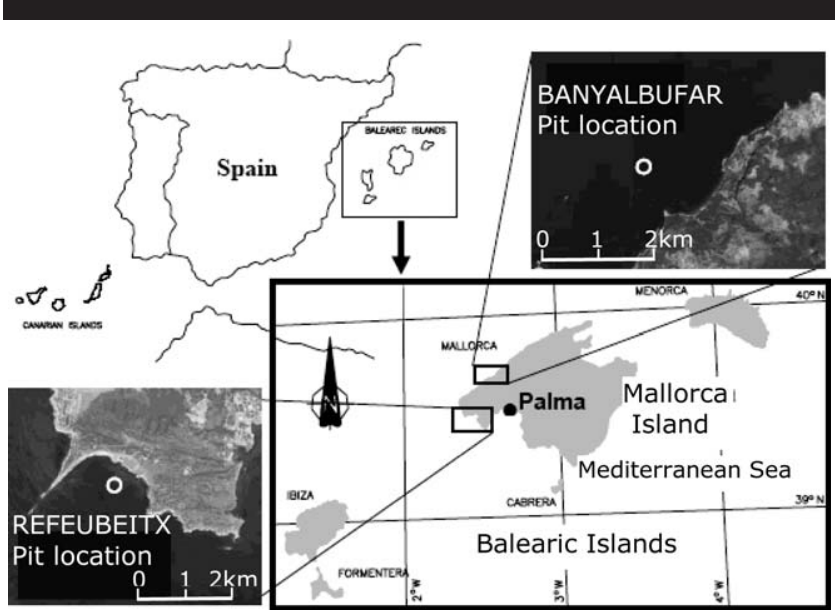

Figure 1. Location of Banyalbufar and Refeubeitx borrow areas in Mallorca Island (Balearic Islands, Spain).

offshore borrow areas. The paper is structured as follows. In the next section, the study site and data available for the morphodynamic analysis and verification of the model are described. The numerical model is then briefly discussed. Finally, the data analysis and results of the simulations are presented with some general recommendations regarding pit design in offshore borrow areas.

\section{STUDY AREA AND FIELD DATA}

The Banyalbufar and Refeubeitx borrow areas are located on the continental shelf of Mallorca Island (Balearic Islands, Spain). The former is located on the west coast, and the latter is located at the southwestern tip of Mallorca Island (see Figure 1). The coast in this area is composed of rocky cliffs and gravel beaches. The Banyalbufar mining area is located $800 \mathrm{~m}$ from the coast, at $35 \mathrm{~m}$ water depth, exposed to the open sea. The Refeubeitx borrow area is located $300 \mathrm{~m}$ offshore of the coast, at $20 \mathrm{~m}$ water depth and wedged between rocky capes in a protected zone, compared with the Banyalbufar borrow zone (see Figure 1).

\section{Morphological Characterization of the Borrow Areas}

\section{Banyalbufar Borrow Area}

As a consequence of consecutive big storm waves occurring in the Balearic Islands in November and December 2001, some of the popular touristic sandy beaches on the islands suffered important shoreline erosion. The Ministry of the Environment started an emergency plan to recuperate the beaches, with Banyalbufar being one of the sand borrow areas. In this borrow area only one dredging event was carried out between April and May 2002. The amount of sand dredged was $207,000 \mathrm{~m}^{3}$. Between 1992 and 2005 several studies were carried out in this zone including data collection before, during, and after the dredging. The field data set includes the following physical information obtained pre- and post dredging in the borrow area: bathymetries; geophysical profiles; bottom morphology obtained with a side scan sonar and underwater video camera; sediment samples inside the pit and the undisturbed seabed 
Table 1. Postdredged measured parameters in the Banyalbufar borrow area (pit geometry and sediment size). Baseline condition in July 2002 and final control condition in July 2005. See Figure 2 for definitions of pit geometry.

\begin{tabular}{|c|c|c|c|c|c|c|c|c|}
\hline \multicolumn{5}{|c|}{ Pit Geometry and Location } & \multicolumn{4}{|c|}{ Sediment Characteristics } \\
\hline Banyalbufar (Field data) & $\begin{array}{c}\bar{b} p \\
(\mathrm{~m})\end{array}$ & $\begin{array}{c}\bar{d}_{p} \\
(\mathrm{~m})\end{array}$ & $\begin{array}{c}\bar{l}_{p} \\
(\mathrm{~m})\end{array}$ & $\begin{array}{l}\bar{h}_{0} \\
(\mathrm{~m})\end{array}$ & $\begin{array}{c}\bar{D}_{50} \\
(\mathrm{~mm})\end{array}$ & $\begin{array}{c}\bar{D}_{90} \\
(\mathrm{~mm})\end{array}$ & $\begin{array}{c}\bar{\rho}_{s} \\
\left(\mathrm{~kg} / \mathrm{m}^{3}\right)\end{array}$ & $\begin{array}{c}\text { Porosity } \\
\varepsilon\end{array}$ \\
\hline Baseline July 1, 2002 & 250 & 1.00 & 830 & 35 & 0.2 & 0.65 & 2650 & 0.4 \\
\hline Pit condition in July 1, 2005 & $\sim 250$ & $\sim 0.85$ & $\sim 830$ & 35 & & & & \\
\hline
\end{tabular}

areas (around the trench) by means of vibrocorer or Van Veen grab sampler. A detailed description of the studies and field data collected in this zone can be consulted in Conselleria de Medi Ambient de les Illes Balears (2006).

The morphological postdredging parameters measured in Banyalbufar's pit are summarized in Table 1 (a description of the geometry parameters for a pit are shown in Figure 2), where $b_{p o}$ is the mean width of the pit; $d_{p o}$ corresponds with the mean dredged pit depth measured from original sea bottom; $l_{p o}$ is the mean length of the pit (the longest dimension); $h_{o}$ is the mean water depth in the undisturbed sea bed area around the pit; $D_{50}, D_{90}, \rho_{s}$, and $\varepsilon$ are, respectively, the median grain size, grain size such that $90 \%$ of the material in the sample is finer, sediment density, and porosity of bed material (mean values in the undisturbed seabed areas around the pit). The parameters measured immediately after the dredging in July 2002 correspond to the baseline condition used in the numerical simulations. The parameters measured in July 2005 correspond to the control condition for the model validation. It is noted from field data that the pit width $\left(b_{p o}\right)$ and pit length $\left(l_{p o}\right)$ have not had significant changes after 3 years, and for this reason, these parameters have been taken as constant in the numerical simulations. The dredged volumes in July 2002 and in July 2005 are shown in Table 2 . This table also shows that 3 years after the dredging at Banyalbufar, around $30,000 \mathrm{~m}^{3}$ of sand had accumulated inside the pit, which corresponds to $14 \%$ of the original dredged volume (recuperation ratio in volume). Finally, the pit migration distance of the pit was between 25 to $35 \mathrm{~m}$ (mean value $\sim 30 \mathrm{~m}$ ).

\section{Refeubeitx Borrow Area}

In the Refeubeitx area two dredging campaigns were carried out in the same place. The first was during May to June of 1994, with $500,000 \mathrm{~m}^{3}$ of sand dredged, and the second was in May 1996 with 110,000 $\mathrm{m}^{3}$ of sand dredged. Between 1989 and 2005 several studies have been carried out in this area, including data collection before, during, and after dredging works. The fieldwork allowed the collection of information similar to that of the Banyalbufar borrow area and the characterization of the pit before and after dredging. A detailed description about the studies and field data collected in this zone can also be consulted in Conselleria de Medi Ambient de les Illes Balears (2006) and Orfila et al. (in press) and Martin et al. (in press).

The morphological postdredging measured parameters in the Refeubeitx pit are summarized in Table 3. In this table the two dredges are characterized, with a first baseline condition on July 1, 1994, and a control condition just before the second dredge work on June 25,1996 . The second baseline condition is just after dredging on July 10, 1996, and the control condition is on July 1, 2005. Sandpit evolution (accumulated volume of sand and pit migration) regarding the two periods in Refeubeitx is shown in Table 4. In this table, it is shown that 2 years after the first dredge in Refeubeitx, around $38,000 \mathrm{~m}^{3}$ of sand have been accumulated inside the pit, which corresponds to $8 \%$ of the original dredged volume (pit volume recuperation). Regarding the second dredging event, $160,000 \mathrm{~m}^{3}$ of sand have been accumulated inside the pit after 9 years, which corresponds to $28 \%$ of the original dredged volume. Finally, the mean pit migration distance of the pit was around 15 and $40 \mathrm{~m}$, for the two periods, respectively.

\section{Marine Dynamic Characterization of the Borrow Areas}

The morphodynamic evolution of the sandpits is mainly governed by the action of the wave climate and currents. The effect of the waves is that of an intensified stirring action in the near-bed region resulting in larger sediment concentrations in

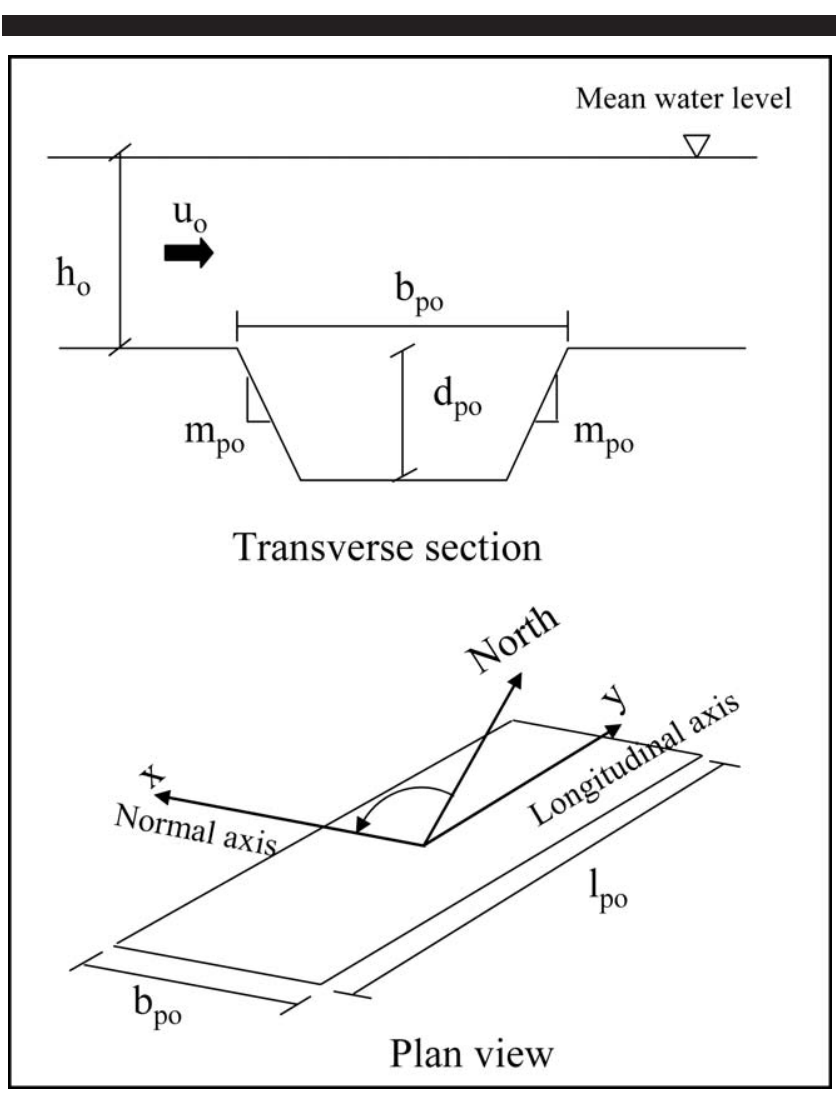

Figure 2. Scheme to represent the geometry of the pit and axes orientation. 
Table 2. Sandpit evolutions in the Banyalbufar borrow area. Accumulated volume of sand and migration distance of the pit (3 years, from 2002 to 2005). Data obtained from field campaigns.

\begin{tabular}{|c|c|c|c|c|c|c|}
\hline $\begin{array}{c}\text { Banyalbufar Sandpit } \\
\text { Evolution }\end{array}$ & $\begin{array}{c}\text { Pit Volume } V_{0} \text { in } \\
2002\left(\mathrm{~m}^{3}\right)\end{array}$ & $\begin{array}{l}\text { Measured Volume, } \\
V_{1} \text { in } 2005\left(\mathrm{~m}^{3}\right)\end{array}$ & $\begin{array}{l}\text { Accumulated Volume } \\
\text { of Sand }\left(\mathrm{m}^{3}\right)\end{array}$ & $\begin{array}{l}\text { Mean Infill } \\
\text { Rate }\left(\mathrm{m}^{3} / \mathrm{y}\right)\end{array}$ & $\begin{array}{c}V_{1} / V_{0} \times \\
100 \%\end{array}$ & $\begin{array}{l}\text { Mean Migration } \\
\text { Distance } \Delta x(\mathrm{~m})\end{array}$ \\
\hline 2002 to 2005 (3 years) & $207,000 *$ & $\sim 177,000$ & $\sim 30,000$ & $\sim 10,000$ & $85 \%$ & $\sim 30$ \\
\hline
\end{tabular}

* The postdredged pit volume corresponds with the dredged volume.

the column of water. This stirring effect diminishes with increasing water depth. Once the sediment is entrained into the water column, the current transports the sediment. In this section, time series of local hydrodynamics (waves and currents) in the pits corresponding to the periods displayed in the previous section are presented. The series span starts from a baseline (morphological condition just after dredging) and ends when another morphological condition is available. In Banyalbufar only one period was defined between July 1, 2002, and July 1, 2005 (3 years). In Refeubeitx two periods were defined between July 1, 1994, and June 30, 1996 (2 years) and between July 10, 1996, and July 1, 2005 (9 years).

\section{Wave Climate}

Deep water wave data $\left(H_{s}, T_{p}, \theta\right)_{\infty}$ including the spectral characteristics were obtained from the oceanographic database of the Spanish holding of harbors, Puertos del Estado (PE), specifically from the SIMAR-44 (time series 1958-2001) and WANA (time series 1996-2007) data set, which provides time series of wave and wind parameters obtained by numerical modeling. Wave fields are generated by means of the third generation wave model WAM (Wamdi Group, 1988; WAM cycle 4: Gómez and Carretero, 1997; Günther, Hasselmann, and Janssen, 1991; Gunther et al., 1992;), which is forced by wind fields. The WAM cycle 4 grid has a resolution of $0.125^{\circ}(15 \mathrm{~km})$ in the Mediterranean. The deep waters grid points WANA-2068038 $\left(39.75^{\circ} \mathrm{N}, 2.59^{\circ} \mathrm{E}\right)$ was used for Banyalbufar and the point WANA$2067036\left(39.50^{\circ} \mathrm{N}, 2.38^{\circ} \mathrm{E}\right)$ for Refeubeitx (approximately $5 \mathrm{~km}$ offshore from the borrow areas in water depths of $120 \mathrm{~m}$ ). Two scalar buoy measurements, Capdepera $\left(39.65^{\circ} \mathrm{N}, 3.49^{\circ} \mathrm{E}\right)$ and Maó $\left(39.72^{\circ} \mathrm{N}, 4.44^{\circ} \mathrm{E}\right)$ and satellite altimeter data (Topex-Poseidon Mission) were used in this work for calibration and verification of hindcasted model results. Spatial and temporal optimization methods have been applied to obtain continued data series (Tomás, Méndez, and Losada, 2008), which are available from the period of February 1994 to April 2006, with a 3-hour interval.

A wave propagation study was carried out to propagate the time series of waves from deep waters (WANA point) to the pit location, taking into account the influence of the islands and local geographic features. Discrete bathymetric and costal boundary data were recomposed using local bathymetries from the field campaigns in the borrow areas, combined with bathymetry from the nautical charts of the Instituto Hidrográfico de la Marina (chart numbers 47, 48, 48e). The Oluca-SP wave spectral model (Gioc, 2003), which is included in the Coastal Modeling System (SMC) (González et al., 2007), was applied to propagate waves from deep waters to the borrow areas. Oluca-SP is a weakly nonlinear combined refraction and diffraction model, which is based on the parabolic approximation solution to the mild-slope equation (Kirby and Dalrymple, 1992, Kirby and Özkan, 1994). Based on the deep water series of waves in the WANA point, 100 JONSWAP spectral shapes were characterized as representatives of the deep water sea states. The $100 \mathrm{JONSWAP}$ spectra, represented as $\left(H_{s}, T_{p}, \theta\right.$, and $\gamma)_{\infty}$ with $\gamma$ as the peak enhancement factor, were combined with different tidal level conditions and propagated to the sandpit areas using the spectral propagation model Oluca-SP. Several transfer interpolation functions were obtained from the WANA points to the different points around the undisturbed seabed areas near the pits. Thus, the 11-year offshore wave data with a 3-hour interval has been transferred to the borrow areas. The local time series of significant wave heights $\left(H_{s o}\right)$ and the directional distribution of the wave heights for Refeubeitx and Banyalbufar are shown in Figures 3a, b, and c. It is noted in the Banyalbufar series (Figure 3a), a big storm occurred in November 2001 with $\left(H_{s o}=9.5 \mathrm{~m}\right.$ and peak period $T_{p o}=10 \mathrm{~s}$.). However, in Refeubeitx the wave height for the same event is significantly smaller $\left(H_{s o}=5.8 \mathrm{~m}\right.$, see Figure $3 \mathrm{~b}$ ) as a resut of the protection of the local capes. A general chart with wave models, sequence, domain size, and grid resolution is shown in Figure 4.

\section{Currents and Sea Level}

The current system in the Balearic Islands is influenced by large-scale dynamics (e.g., Eastern Mediterranean basin, Algeria Basin) and local circulation affected by local winds

Table 3. Postdredged measured parameters in the Refeubeitx borrow area (pit geometries and sediment sizes). Baseline conditions in July 1994 and July 1996. Final control conditions in June 1996 and July 2005.

\begin{tabular}{|c|c|c|c|c|c|c|c|c|c|}
\hline \multirow[b]{2}{*}{ Refeubeitx (field data) } & & \multicolumn{4}{|c|}{ Pit Geometry and Location } & \multicolumn{4}{|c|}{ Sediment Characteristics } \\
\hline & & $\begin{array}{l}\bar{b}_{p} \\
(\mathrm{~m})\end{array}$ & $\begin{array}{l}\bar{d}_{p} \\
(\mathrm{~m})\end{array}$ & $\begin{array}{c}\bar{l}_{p} \\
(\mathrm{~m})\end{array}$ & $\begin{array}{l}\bar{h}_{0} \\
(\mathrm{~m})\end{array}$ & $\begin{array}{c}\bar{D}_{50} \\
(\mathrm{~mm})\end{array}$ & $\begin{array}{c}\bar{D}_{90} \\
(\mathrm{~mm})\end{array}$ & $\begin{array}{c}\bar{\rho}_{s} \\
\left(\mathrm{~kg} / \mathrm{m}^{3}\right)\end{array}$ & $\begin{array}{c}\text { Porosity } \\
\varepsilon\end{array}$ \\
\hline \multirow{2}{*}{$\begin{array}{l}\text { Spring } 1994 \text { Dredged } \\
\quad \text { volume } 500,000 \mathrm{~m}^{3}\end{array}$} & Baseline July 1, 1994 & 160 & 5.7 & 550 & 20 & 0.35 & 0.7 & 2650 & 0.4 \\
\hline & $\begin{array}{l}\text { Pit condition June 25, } \\
1996\end{array}$ & $\sim 160$ & $\sim 5.25$ & $\sim 550$ & 20 & & & & \\
\hline \multirow{2}{*}{$\begin{array}{l}\text { May } 1996 \text { Dredged } \\
\quad \text { volume } 110,000 \mathrm{~m}^{3}\end{array}$} & Baseline July 101996 & $\sim 160$ & 5.5 & $\sim 650$ & 20 & $\sim 0.35$ & $\sim 0.7$ & 2650 & 0.4 \\
\hline & $\begin{array}{l}\text { Pit condition July } 1 \text {, } \\
2005\end{array}$ & $\sim 160$ & $\sim 3.96$ & $\sim 650$ & 20 & & & & \\
\hline
\end{tabular}


Table 4. Sandpits evolution in the Refeubeitx borrow area. Accumulated volume of sand and migration distance of the pit in two periods (2 years, from 1994 to 1996 and 9 years, from 1996 to 2005). Data obtained from field campaigns.

\begin{tabular}{|c|c|c|c|c|c|c|}
\hline Refeubeitx Sandpit Evolution & Pit Volume $V_{0}$ & Measured Pit Volume $V_{1}$ & $\begin{array}{c}\text { Accumulated Volume } \\
\text { of Sand }\left(\mathrm{m}^{3}\right)\end{array}$ & $\begin{array}{l}\text { Mean Infill } \\
\text { Rate }\left(\mathrm{m}^{3} / \mathrm{y}\right)\end{array}$ & $\begin{array}{c}V_{1} / V_{0} \times \\
100 \%\end{array}$ & $\begin{array}{l}\text { Mean Migration } \\
\text { Distance } \Delta x(\mathrm{~m})\end{array}$ \\
\hline 1994-1996 (2 y) & $500,000 *($ in 1994$)$ & $\sim 462,000 \dagger$ & $\sim 38,000$ & $\sim 19,000$ & $92 \%$ & $\sim 15$ \\
\hline 1996-2005 (9 y) & $\sim 572,000($ in 1996$)$ & $\sim 412,000$ (in 2005$)$ & $\sim 160,000$ & $\sim 17,800$ & $72 \%$ & $\sim 40$ \\
\hline
\end{tabular}

* The post-dredged pit volume corresponds with the dredged volume.

${ }^{\dagger}$ Approximate measured volume in 1996, before the second dredge.

combined with marine and atmospheric fronts. Additionally, the complex topo-bathymetry of the islands makes it a very complex circulation system. In this work the current time series in the borrow areas has been obtained by means of the numerical simulation of the forcing terms in different scales, as follows: (1) the baroclinic circulation with important variations on a time scale of months; (2) the tidal forcing with variations from hours to days has been also included, even though its influence is very small as was verified in the study; and (3) the current system forced with local winds with variations on a time scale of hours. Based on the different time scales of the variation of the previous forcing terms, their linear superposition was assumed. Time series in the borrow areas were
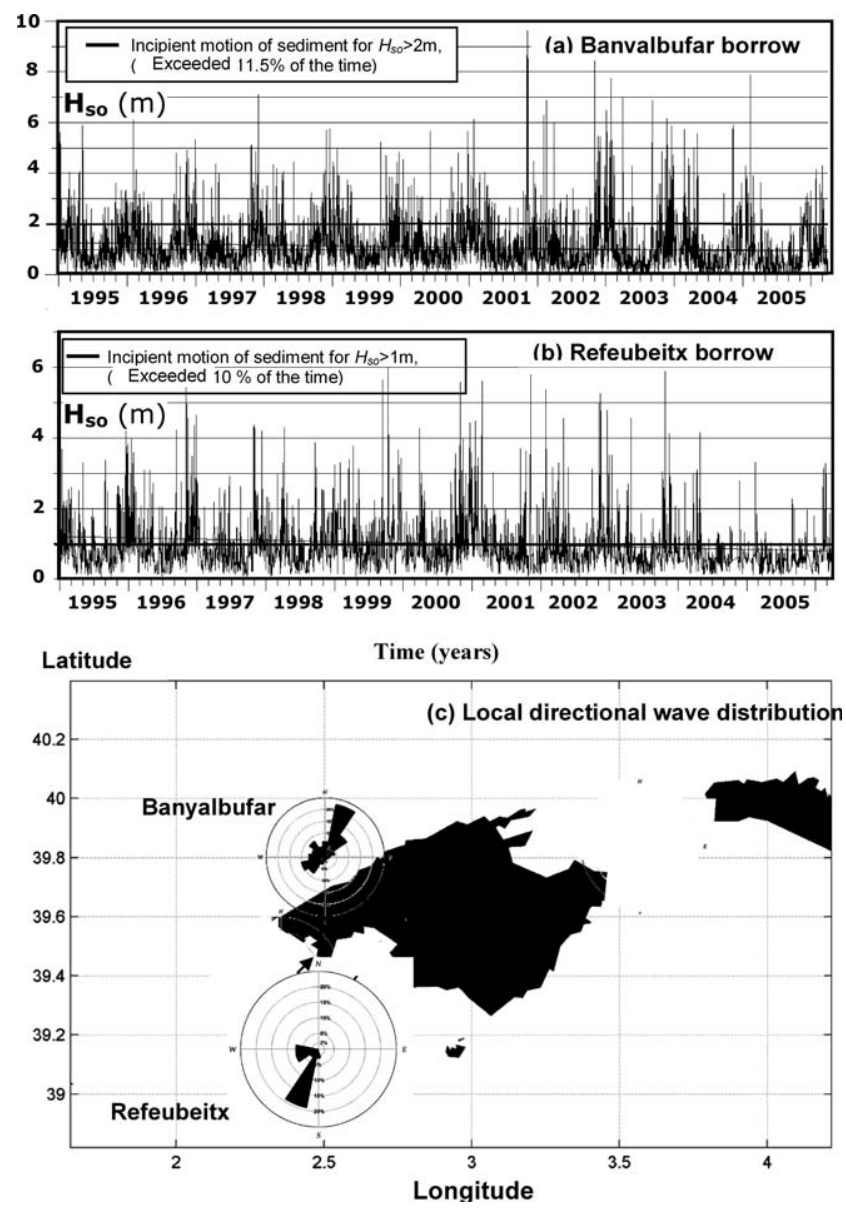

Figure 3. Significant wave height time series $\left(H_{\text {so }}\right)$ in the borrow areas: (a) Banyalbufar, (b) Refeubeitx, and (c) directional wave height distribution. generated independently for each current system and linearly combined (some tests were carried out to validate the hypothesis of linear superposition of the currents). A general chart with the applied flow models, size domains, and grid resolutions is shown in Figure 4. The final current system has been validated using previous works including numerical simulations and measurements in situ (Demoriv and Pinardi, 2002; Fernández, 2004; Font, Salat, and Tintoré, 1998; Werner, Viúdez, and Tintoré, 1993).

The baroclinic current time series in the borrow zones was obtained applying the DieCast Model to the Mediterranean basin. The purely z-level DieCAST Ocean Model (Dietrich, 1997; Dietrich, Marietta, and P.J. Roache, 1987) solves the discretized hydrostatic, incompressible conservation equations that are in integrated "control volume" form within each control volume of each grid. Vertical mixing by subgrid-scale eddies is parameterized by eddy diffusivity (for temperature and salinity) and viscosity (for momentum), using a modified Richardson number approach (Staneva et al., 2001) based on Pacanowski and Philander (1981). Common instant convective adjustment is not invoked. The Mediterranean bathymetry was obtained from the ETOPO2 database, with a 2-minute latitude-longitude grid resolution. The wind forcing of DieCAST is obtained from interpolated the hourly SIMAR-44 and WANA wind database (Eppe, 2003). The same is done with the heat fluxes. Levitus climatology is used to initialize DieCAST and to determine the corrections for the surface sources of heat and fresh water (e-p) using the nondamping precise approach described by Dietrich $e t$ al. (2004). An average circulation system for October 1, 2000, is shown in Figure 5. In general, the flow reaches almost normal to the pits (parallel to $x$-axis, Figure 2); the mean annual velocity in Refeubeitx is $V_{m}=0.07 \mathrm{~m} / \mathrm{s}$, in Banyalbufar it is $V_{m}=0.09 \mathrm{~m} / \mathrm{s}$, with maximal monthly velocities between 0.2 and $0.8 \mathrm{~m} / \mathrm{s}$ in Refeubeitx and 0.3 and $0.9 \mathrm{~m} / \mathrm{s}$ in Banyalbufar.

The H2D Model was used to simulate tidal and wind-driven circulation in the study area. The model uses the Reynolds depth-averaged, Navier-Stokes equations with hydrostatic assumption. Earlier morphodynamic studies (e.g., Roos, Hulscher, and De Vriend,, 2008; Sandpit, 2005) applies a depth-averaged flow module under similar marine morphodynamic conditions (offshore sandpits with $h_{o}>20 \mathrm{~m}, b_{p o} / h_{o}<$ $10, d_{p o} / h_{o}<0.2$, tidal periods $T=12.42 \mathrm{~h}$ ). The model was calibrated using the tidal gauge in Ibiza $\left(38.91^{\circ} \mathrm{N}, 1.44^{\circ} \mathrm{E}\right)$. The model was driven along the open boundaries, using the diurnal $\left(K_{1}, O_{1}, P_{1}\right.$, and $\left.S_{1}\right)$ and semidiurnal $\left(K_{2}, M_{2}, N_{2}\right.$, and $\left.S_{2}\right)$ tidal constituents. Amplitudes and phases were obtained from the harmonic analysis of the Ibiza tidal gauge, the tidal period dominated by the semidiurnal lunar component $M_{2}, T=$ $12.42 \mathrm{~h}$. Sea level and velocity series with a 3 -hour time interval have been obtained for different points around the 




Figure 4. General chart with the applied wave models, flow models, size domains, and grid resolutions.

undisturbed seabed areas near the two pits. As was pointed out previously, tidal currents are an order of magnitude smaller than the combined baroclinic and wind currents.

Local wind-induced currents around the islands were simulated using the H2D model with a $50-\mathrm{m}$ grid resolution using the local high resolution bathymetries. Winds were obtained from SIMAR-44 and WANA wind data (3-hour time interval). In accordance with the wind regimens, the mean wind velocity is around $5 \mathrm{~m} / \mathrm{s}$, the annual extreme wind is around $18 \mathrm{~m} / \mathrm{s}$, and the 25-year return period is $25 \mathrm{~m} / \mathrm{s}$, with dominant winds coming from north to northeast. To transfer wind velocities to water velocities in the borrow areas, a procedure similar to the one developed with waves has been carried out. Based on 50 wind cases obtained as a combination of representative winds in the study area (velocity: $V_{w}[\mathrm{~m} / \mathrm{s}]$ and directions: $\theta_{w}$ ), and using the H2D model, several transfer interpolation functions (current velocity $v s$. wind velocity) have been obtained for different points around the undisturbed seabed areas near the two pits. Thus, a 3hour time interval water current has been obtained for the borrow areas using SIMAR-44 and WANA wind data combined with the interpolation functions.

\section{MORPHODYNAMIC EVOLUTION MODEL OF PITS}

The morphological and dynamic conditions in the borrow areas, combined with the geometry and orientation of the pits, permit the treatment of the morphological development of the pits as a one-dimensional problem in flow $(x-)$ direction. In both pits, the principal axis $(y$-) is normal to the direction of the steady currents, and the surrounding seabed areas can be assumed to be horizontal (see axis orientation in Figure 2). Furthermore, regarding the geometry of the pits, it can be assumed that the pits are short and shallow. Hence, the vertical acceleration of the flow can be assumed to be negligible and the pressure to be hydrostatic, which means that the flow is governed by the shallow-water equations. The morphodynamic model applied in this study is based on the analytical engineering formulations presented by Ribberink, Roos, and Hulsater (2005) and Ribberink (2004). In this section, a brief description of the basic equations and the analytical morphodynamic evolution model are presented. A more detailed derivation of the model can be consulted in Ribberink, Roos, and Hulsater (2005) and Ribberink (2004). Next, the implementation of the analytical morphodynamic evolution model into a numerical model applicable to marine environments is described. It requires some modification in the initial and boundary conditions.

\section{Basic Equations}

The analytical morphodynamical model is based on: (1) shallowwater flow equations; (2) near-bed wave orbital flow; (3) sediment transport formulations; and (4) sediment continuity equation. 


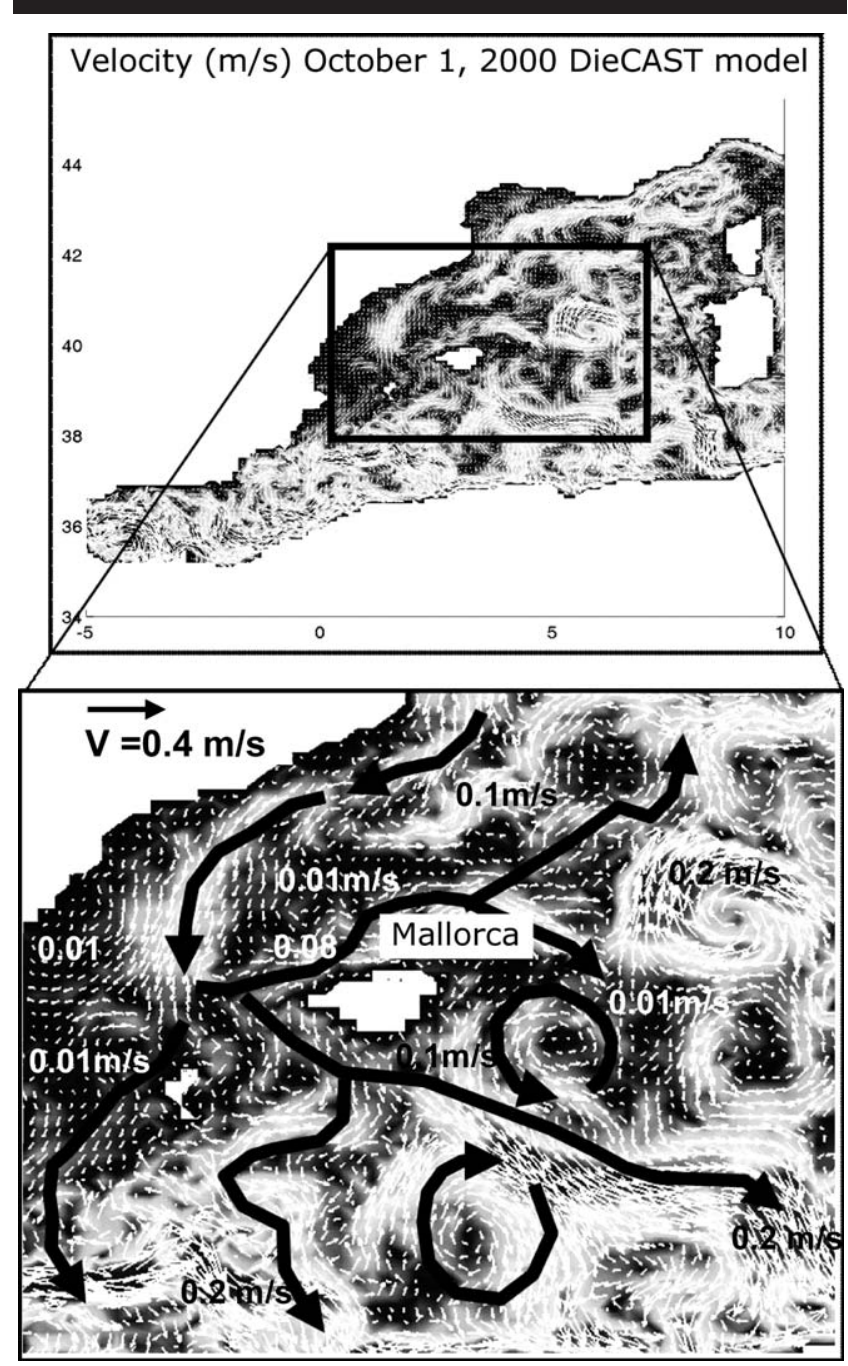

Figure 5. Numerical simulation example of the baroclinic flow velocities with the Diecast model in the western Mediterranean (October 1, 2000).

\section{Flow}

The one-dimensional shallow-water flow equations (continuity and momentum) are applied. In accordance with Ribberink, Roos, and Hulsater (2005), in a marine environment with tidal periods $T=12.42 \mathrm{~h}$, water depths $h_{o}=10-30 \mathrm{~m}$ (see parameter description in Figure 2), depth averaged flow velocities $u_{o}=0-2 \mathrm{~m} / \mathrm{s}$, small Froude numbers $\left[F_{r o}=u_{o} /\right.$ $\left(g h_{o}\right)^{0.5}<<1$, where $g$ is the acceleration of gravity] and for short pit widths $\left(5<b_{p o} / h_{o}<50\right)$, the scale of the advection, acceleration, and friction terms are much smaller than the bedand water level gradient terms. Thus, the continuity and momentum equations can be simplified to the linear quasisteady equations.

It is assumed that waves in deep waters (significant wave height $H_{s o}$ and peak period $T_{p o}$ ) are spatially constant and are not affected by the pits and currents. Therefore, linear wave theory is valid for the description of the near-bed wave orbital flow.

\section{Sediment Transport}

Using the time-averaged formulation over the wave period (Bailard, 1981), we split the total sediment transport $\left(q_{t}\right)$ into a bed-load $\left(q_{b}\right)$ plus a suspended-load $\left(q_{s}\right)$ rate because $q_{t}=q_{b}+$ $q_{s}$. The bed-load transport is obtained as a function of the local hydrodynamic and sediment parameters using the analytical approximation of the energetics-type bed-load formulation of Bailard (1981). Suspended sediment transport has been calculated as a function of the flow $\left(u_{o}\right.$ and $\left.h_{o}\right)$ and the depthaveraged suspended sediment concentration, which has been described by Galappatti and Vreugdenhil (1985) as an asymptotic solution of the 3D advection-diffusion equation. In this equation the equilibrium concentration is defined using an analytical approximation of the velocity power function in the suspended-load transport model of Bailard (1981). Bailard's (1981) bed- and suspended-load transport model takes into account the combined effect of waves and currents, the diffusion induced by the bottom slope, and the lag between the flow and the sediment transport in suspension.

\section{Bed Level Changes}

Bed-level changes are calculated with the continuity equation for sediments.

\section{Morphodynamic Evolution Model}

After some derivation combining the previous basic equations (see Ribberink, 2004 and Ribberink, Roos, and Hulsater, 2005), the single differential equation for bed level is as follows:

$$
\frac{\partial z_{b}}{\partial t}+c \frac{\partial z_{b}}{\partial x}+D \frac{\partial^{2} z_{b}}{\partial x^{2}}+L_{A} \frac{\partial^{2} z_{b}}{\partial x \partial t}+P \frac{\partial^{3} z_{b}}{\partial x^{3}}=0,
$$

where

$$
\begin{aligned}
c= & c_{b}+c_{s} \text { advection velocity of the seabed } \\
c_{b}= & \text { migration velocity due to bed-load } \\
c_{s}= & \text { migration velocity due to suspended-load } \\
D= & L_{A} c_{b}+D_{i b} \text { diffusion coefficient } \\
D_{i b}= & \text { diffusion coefficient due to bed-slope effect (see } \\
& \text { Appendix A) } \\
L_{A}= & \text { adjustment length for suspended sediment (see } \\
& \text { Appendix A) } \\
P= & L_{A} D_{i b}
\end{aligned}
$$

A harmonic analysis shows that a sinusoidal bed wave of the pit is the solution of Equation (1) (see Figure 6):

$$
z_{b}(x, t)=a e-\frac{t}{T_{\text {bed }}} e^{i k\left(x-c_{\text {bed }} t\right)}
$$

where

$$
\begin{aligned}
C_{\text {bed }}= & \text { migration velocity } \\
T_{\text {bed }}= & \text { amplitude decay time or e-folding time } \\
a \quad= & \text { initial amplitude (see Figure } 6) \\
k \quad= & \text { bottom wave number }(=2 \pi / L) \text { with } L \text { as bottom } \\
& \quad \text { wavelength } \\
t \quad= & \text { time } \\
x \quad= & \text { position along the pit }
\end{aligned}
$$

Ribberink (2004) proposed some analytical relationships for 


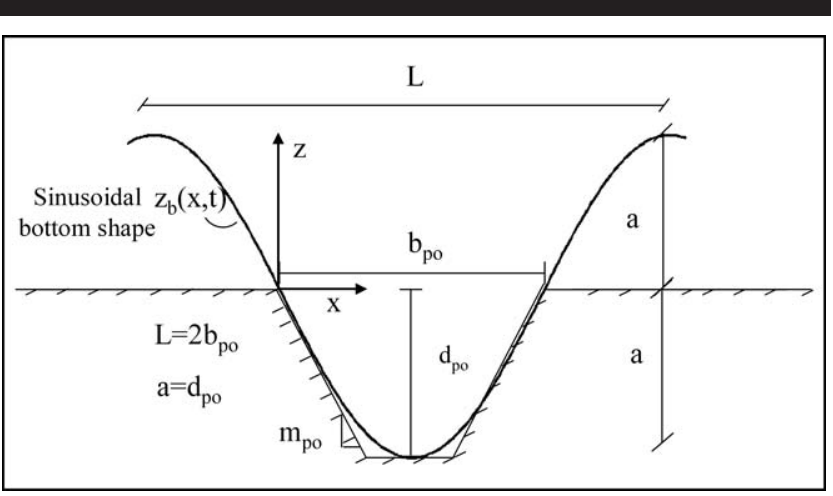

Figure 6. Scheme to represent the initial condition of the pit geometry, in accordance with the sinusoidal analytical model of Ribberink, Roos, and Hulsater (2005).

$C_{\text {bed }}$ and $T_{\text {bed. }}$ These expressions can be defined in accordance with the dominant flow: If the near-bed flow velocity $\left(u_{b o}\right)$ is bigger than the amplitude of the near-bed horizontal orbital wave velocity $\left(\hat{U}_{o}\right)$, the current dominates over the wave $\left(u_{b o}>\right.$ $\hat{U}_{o}$ ). Otherwise, wave dominates over current when $u_{b o}<\hat{U}_{o}$. $C_{\text {bed }}$ and $T_{\text {bed }}$ can be obtained as a function of constant parameters throughout time defined in the undisturbed condition upstream and far downstream of the pit, as follows: flow parameters $\left(u_{b o}, \hat{U}_{o}, H_{s o}, T_{p o}, h_{o}\right)$; the sediment characteristics (settling velocity of sediment $\omega_{s}$, median grain size $D_{50}$, sediment density $\rho_{s}$, angle of repose $\left.\phi_{\mathrm{o}}\right)$; the sediment transport $\left(q_{t}=q_{s}+\right.$ $q_{b}$ ), including some velocity and concentration profile coefficients $\left(\alpha_{b}, \alpha_{s}, L^{\prime}\right.$ with standard value $\left.=0.5\right)$, and the efficiency factors for the Bailard formula $\left(\varepsilon_{b}=0.1, \varepsilon_{s}=0.02\right)$; and the initial geometry of the pit $\left(b_{p o}, d_{p o}, m_{p o}\right)$. Expressions used for $C_{\mathrm{bed}}$ and $T_{\text {bed }}$ in this work are presented in Appendix A. The subscript ()o refers to the undisturbed condition, not affected by the pit. A more complete description can be consulted in Ribberink (2004).

A schematic representation of the initial condition of the geometry of the pit for the sinusoidal analytical solution [Equation (2)] is presented in Figure 6. The flow and sediment parameters are defined as an initial condition, constant throughout time.

\section{Model Validation}

This model has been verified in the frame of the SANDPIT Project using (1) the numerical evolution model LOMOR (Ribberink, 1989; Van Alphen et al., 1990), see tests and results in Ribberink (2004); (2) measured trench evolutions of two laboratory experiments, a flume experiment (Van Rijn, 1986) and a wave basin experiment (Havinga, 1992); and (3) a first rough validation carried out along the Dutch coast (Scheveningen). The pit was $45 \mathrm{~m}$ wide, $3.5 \mathrm{~m}$ deep, in a water depth of $8 \mathrm{~m}$; it was dredged in 1964 (see details in Svasek, 1965). Details about the validation of the harmonic analytical solution in the laboratory and previous field cases can be consulted in Ribberink, Roos, and Hulsater (2005). These authors concluded that "using relatively small calibration factors for the sediment transport (range: 0.5-1) the migration and infill behaviour of the trenches could be well described in a qualitative as well as in a quantitative sense." However, more refined verifications with field cases are still recommended by these authors.

\section{Model Implementation}

The implementation of the previously described analytical model into a numerical model applicable to marine environments requires some modifications in the initial and boundary conditions. A spectral model approach can be applied to the linearized Equation (2) to calculate the evolution of an arbitrary-shaped pit (Roos, 2004) whenever the initial geometry fit with a shallow pit $\left(d_{p o} / h_{o}<0.2\right)$. Under this situation the linearized evolution Equation (2) is still valid. In this study the initial condition for the pit geometries is represented by a trapezoidal shape. Following Ribberink, Roos, and Hulsater (2005), the pits have been represented as a Fourier series of different bed wavelengths. The initial condition for the pit geometry is represented as

$$
z_{b}(x, t=0)=\frac{d_{p o}}{2}+\frac{2 b_{p o}}{\pi^{2}} \sum_{n=1}^{k} \frac{(-1)^{n}}{n^{2}} \cos \frac{n \pi x}{b_{p o}}
$$

The evolution of each sinusoidal bed wave is calculated applying Equation (2), and the morphological evolution of the pit in a given time is obtained as a superimposition of all bed waves.

On the other hand, the dynamics (waves and currents) are not constant in marine environments. Hence, in the case of long-term simulations $\mathrm{O}$ (years-decades), it is necessary to define long-term arbitrary series of these dynamics defined as temporal boundary conditions for the model. In this study the temporal series of the normal components of the depthaveraged flow to the pits, axis $x$ (see axis orientation in Figure 2), have been defined as follows: baroclinic currents, $u_{\text {baxo }}(t)$; tidal currents, $u_{\text {tixo }}(t)$; wind-induced currents, $u_{w x o}(t)$; and the water depth including tidal oscillations, $h_{o}(t)$. As previously stated, the total flow is the linear superimposition of the normal vectors of these components. In the same way, time series of the wave climate were defined $\left[H_{s o}(t), T_{p o}(t)\right.$, and $\left.\theta_{o}(t)\right]$. All of these time series have been defined in time increments ( $\Delta t=3$ hours) because this is the typical duration of the wave states in the area. The physical characteristics of the fluid and sediment are assumed to be constant throughout the simulation time steps. The analytical model of Ribberink (2004), including the previous boundary conditions, have been implemented in a simple engineering numerical tool denominated Morphodynamic Evolution Model for Pits (MEMPITS).

\section{APPLICATION OF THE MEMPITS MODEL AND RESULTS}

The MEMPITS model has been applied to the Banyalbufar and Refeubeitx borrow areas. The baseline pit conditions and sediment characteristics for the simulations are presented in Tables 1 and 3. The control or "final" evolution conditions to validate the model performance are also shown in Tables 1 to 4 .

\section{Refeubeitx Borrow Area}

Two dredged sandpits in the same location have been simulated in the Refeubeitx borrow area: The first is for a 2 - 
Table 5. Numerical morphodynamic evolution of the sandpits in Banyalbufar and Refeubeitx (calibrated MEMPITS Model).

\begin{tabular}{|c|c|c|c|c|c|c|c|c|c|}
\hline Borrow Areas & Simulation Times & $C_{\text {bed }}(\mathrm{m} / \mathrm{d})$ & $T_{\text {bed }}(\mathrm{y})$ & $\Delta x(\mathrm{~m})$ & $\mathrm{d}_{\mathrm{po}}(\mathrm{m})$ & $d_{p f}(\mathrm{~m})$ & $\begin{array}{c}V_{p 1} / V_{p o} \times \\
100 \%\end{array}$ & $T_{r 50 \%}(\mathrm{y})$ & $T_{r 90 \%}(\mathrm{y})$ \\
\hline Banyalbufar & 2002-2005 (3 y) & 0.022 & 75 & 21 & 1.00 & 0.84 & $85 \%$ & 52 & 172 \\
\hline \multirow[t]{2}{*}{ Refeubeitx } & 1994-1996 (2 y) & 0.012 & 164 & 8 & 5.70 & 5.25 & $92 \%$ & 113 & 376 \\
\hline & $1996-2005(9 \mathrm{y})$ & 0.010 & 174 & 31 & 5.50 & 3.96 & $72 \%$ & 120 & 401 \\
\hline
\end{tabular}

year period and the second is for the 9-year period. The associated time series regarding the dynamics described previously (waves, currents, and sea level) have been defined in time increments ( $\Delta t=3$ hours) as boundary condition for the two periods. In Figure $7 \mathrm{a}$, the temporal evolution of the nondimensional damping parameter defined as the ratio $V_{p 1} /$ $V_{p 0}$ is shown, where $V_{p 1}$ is the pit's volume at the end of the simulation and $V_{p 0}$ is the pit's initial volume. In the same way, the temporal evolution of the nondimensional migration parameter defined as the ratio $x_{c} / b_{p o}$ is shown, where $x_{c}$ is the position of the centroid of the pit volume in $x$ - and $b_{p o}$ is the initial width of the pit. For damping and migration evolution parameters (Figure 7a), the measured nondimensional parameters are included (symbolized by circles for damping and triangles for migration), together with the noncalibrated simulation represented by dashed lines (standard parameters: $\alpha_{b}, \alpha_{s}, L^{\prime}=0.5$, and the efficiency factors for the Bailard formula $\varepsilon_{b}=0.1, \varepsilon_{s}=$ 0.02 , and $\phi=32^{\circ}$ ) and the calibrated simulation to the volume damping ratio, represented by a solid line $\left(V_{p 1} / V_{p 0}=0.92\right.$ in June 1996). A slight tuning of calibration factors only for profile parameters has been necessary $\alpha_{b}, \alpha_{s}, L^{\prime}(=0.58)$.

The morphodynamic evolution of the pit in Refeubeitx is presented in Figure $7 \mathrm{~b}$ and Table 5 . The average migration velocity $C_{\text {bed }}$ is $0.36 \mathrm{~m} / \mathrm{mo}(0.012 \mathrm{~m} / \mathrm{d})$ and the decay time $T_{\text {bed }}$ $=164$ years, with a recuperation time for $50 \%$ and $90 \%$ of the volume $T_{50 \%}$ (=113 years) and $T_{90 \%}$ ( $=376$ years), respectively. These results are of the order of magnitude presented by Boers (2005) and Chesher, Soulsby, and Foley (2005) for pits in water depths greater than $18 \mathrm{~m}$. The average migration distance of the pit $\Delta x(=8 \mathrm{~m})$ is of the same order of magnitude as that measured in field $\Delta x(\sim 15 \mathrm{~m}$ in Table 4$)$.

Regarding the second simulation period, the general behaviour is very similar to the first period. The damping and migration nondimensional parameters and the evolution of the migration velocity are shown in Figure 8 . The calibration parameters are very similar to those obtained in the first case $\alpha_{b}, \alpha_{s}, L^{\prime}(=0.61)$ to fit with the volume damping ratio $\left(V_{p 1} / V_{p 0}\right.$ $=0.72$ in July 2005). It is interesting to point out that the pit damping and migration velocity is incremented with the occurrence of important wave storm events. Figure 8a shows that the decreasing damping curve present increments in slope in the winter seasons (e.g., November 2001 to January 2002), when relevant storms occurred in the area. A similar behaviour is presented in the evolution of the migration velocity $\left(C_{\text {bed }}\right)$ shown in Figure 8b. The damping and the migration velocity of the pit in Refeubeitx is closely related to the occurrence of important local wave storms (stirring effect). The geometry of the pit (very narrow with $b_{p o} / h_{o}=8<10$ ) tends to make migration slow (to be discussed in the next section). On the other hand, the mean condition of the waves and currents in this deep water depth $\left(h_{o}=20 \mathrm{~m}\right)$ is not very strong.
Furthermore, the wave-induced incipient motion of sediment particles from the sea bottom in Refeubeitx (using Shields parameter) starts for $H_{s o}>1 \mathrm{~m}$ (which is only exceeded $10 \%$ of the time; see Figure $3 \mathrm{~b}$ ). However, with big storms, even with small currents, the migration and infilling rates of the pit are incremented in an important way.

The morphodynamic evolution of the 9 -year pit (every 6 months) is presented in Figure 9 and Table 5. The average migration velocity $C_{\text {bed }}$ is $0.3 \mathrm{~m} / \mathrm{mo}(0.01 \mathrm{~m} / \mathrm{d})$ and the decay time $T_{\text {bed }}(=174$ years), with a recuperation time for $50 \%$ and $90 \%$ of the volume $T_{50 \%}$ (= 120 years) and $T_{90 \%}$ (= 401 years), respectively. The average calculated migration distance of the pit $\Delta x(=31 \mathrm{~m})$ is of the same order of magnitude compared with that measured in the field $\Delta x(\sim 40 \mathrm{~m}$ in Table 4$)$.

\section{Banyanbufar Borrow Area}

In this zone, a 3-year period has been simulated. The associated time series regarding the dynamics described previously (waves, currents, and sea level) have been defined as a boundary condition. In this case, in a similar way to Refeubeitx, the pit damping and migration velocity are incremented with the occurrence of important wave storm events. The damping and the migration velocity of the pit in Banyalbufar are also closely related to the occurrence of the important local wave storms

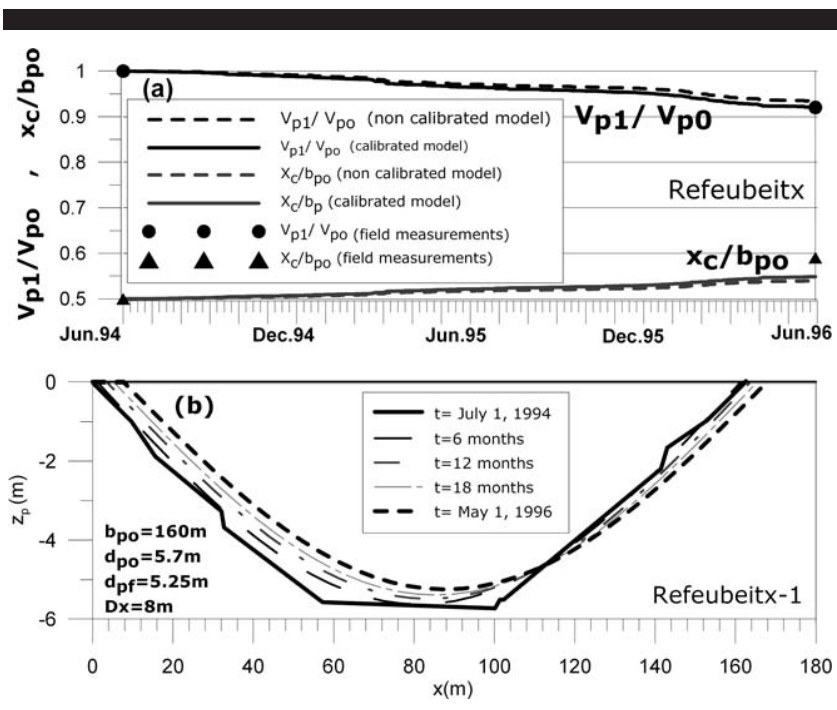

Figure 7. Sandpit morphological evolution in Refeubeitx (July 1, 1994, to May 1, 1996). Comparison of model simulation results with field data: (a) evolution of the damping rate $\left(V_{p 1} / V_{p 0}\right)$, the migration rate $\left(x_{c} / b_{p o}\right)$ and (b) 2-year morphodynamic evolution of the sandpit in Refeubeitx (July 1, 1994, to May 1, 1996). MEMPITS model results based on Ribberink, Roos, and Hulsater (2005). 


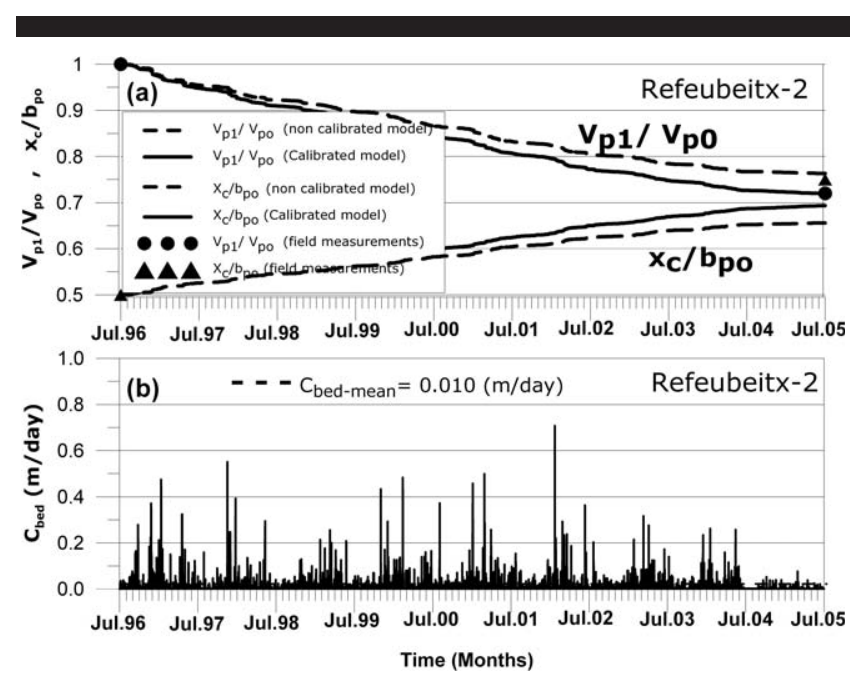

Figure 8. Sandpit morphological evolution in Refeubeitx (July 1, 1996, to July 1, 2005). Comparison of model simulation results with field data: (a) evolution of the damping rate $\left(V_{p 1} / V_{p 0}\right)$, the migration rate $\left(x_{c} / b_{p o}\right)$ and $(\mathrm{b})$ the migration velocity $\left(C_{\text {bed }}\right)$. MEMPITS model results based on Ribberink, Roos, and Hulsater (2005).

(stirring action). The standard parameters for the noncalibrated simulation are the same as shown in Refeubeitx. However, a slight tuning of calibration factors only for profile parameters has been necessary $\alpha_{b}, \alpha_{s}, L^{\prime}(=0.62)$ to fit with the volume damping ratio $\left(V_{p 1} / V_{p 0}=0.85\right.$ in July 2005$)$.

The predicted morphodynamic evolution in Banyalbufar is presented in Table 5 . The average migration velocity $C_{\text {bed }}$ is $0.66 \mathrm{~m} / \mathrm{mo}(0.022 \mathrm{~m} / \mathrm{d})$ and the decay time $T_{\text {bed }}=75$ years, with a recuperation time of $50 \%$ and $90 \%$ of the volume $T_{50 \%}=52$ years and $T_{90 \%}=172$ years respectively. The average migration distance of the pit $\Delta x(=21 \mathrm{~m})$ is of the same order of magnitude compared with that measured in the field $\Delta x$ ( $\sim 30 \mathrm{~m}$ in Table 2$)$. It is noted that the analytical model provides, even without calibration factors, good estimates of the infill ratio and migration velocity of Banyalbufar pit.

\section{DISGUSSION}

In this section a first analysis regarding the performance of the two Balearic sandpits is discussed, taking into account their geometry and dynamic differences. Next, the reason why the migration velocity in Refeubeitx presents a larger deviation (simulations vs. field data) compared with Banyalbufar is discussed. Finally, a sensibility analysis using nondimensional relationships provided by the numerical model is carried out to better understand the relation between local marine dynamics, sediment, and pit geometry.

The simple 1D model provides, with a slight tuning of calibration factors, good estimates of the infill ratio and migration velocity in the offshore Balearic pits. The quantitative and qualitative behaviour obtained with the 1D morphodynamic model agrees with results obtained from earlier studies assuming depth-averaged flow (Roos, Roos, and Hulsater, 2008; Sandpit, 2005). The Refeubeitx pit is located in a shallower water depth $\left(h_{o}=20 \mathrm{~m}<35 \mathrm{~m}\right)$ and has the

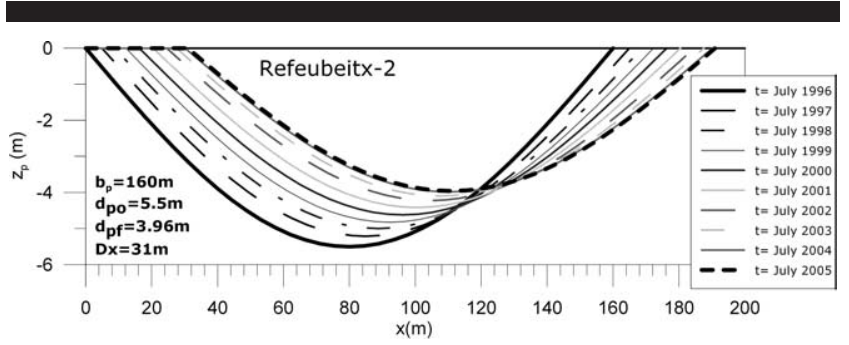

Figure 9. Nine-year morphodynamic evolution of the sandpit in Refeubeitxr (July 1, 1996, to July 1, 2005). MEMPITS model results based on Ribberink, Roos, and Hulsater (2005).

greatest bottom sediment size $\left(D_{50}=0.35 \mathrm{~mm}\right)$ and the wider pit $\left(b_{p o} / h_{o}=8\right)$, and its location is protected from important wave storms and currents, making the migration velocity $\left(C_{\text {bed }}\right)$ smaller and the amplitude-decay time $\left(T_{\text {bed }}\right)$ larger than at Banyalbufar. Therefore the pit in Refeubeitx will require a longer period to recover (decay of the pit depth in time).

In accord with the extensive study by Davies et al. (2002), the morphological time scale and evolution parameters (migration velocity and the amplitude-decay time) are surrounded with a band of uncertainly, estimated up to a factor of 10. For the Balearic sandpits, both migration velocity and the amplitudedecay time from simulations are of the same order of magnitude compared with the field measurements. However, the migration velocity for Refeubeitx presents a greater deviation compared with field data. Its behaviour can be explained because Refeubeitx presents a relative pit depth $\left(d_{p o} / h_{o} \sim 0.25\right)$ deeper than Banyalbufar $\left(d_{p o} / h_{o} \sim 0.03\right)$ that is on the edge of the model's hypothesis. The 1D model assumes linearity in the bed amplitude $\left(d_{p o}<<h_{o}\right)$; therefore, the flow inside the pit is not affected by the pit geometry. However, in deeper pits 3D flows are important and affect the migration process of the pit. Thus, deeper pits may require a 3D rather than a depthaveraged flow approach (Walstra et al., 2002).

In the numerical simulations of the offshore Balearic sandpits, it has been found that waves may speed up the morphodynamic evolution mainly due to stirring effects. This behaviour is important under wave storm conditions. Thus, even when the pit is located offshore, a good local wave climate characterization is important for offshore sandpit numerical simulations.

In accordance with the analytical model [Equations (1) and (2)], $C_{\text {bed }}$ and $T_{\text {bed }}$ govern the morphodynamic evolution of pits and involve the most important process to define their migration and the infill time (damping time). In a similar way to Ribberink (2004) and Ribberink, Roos, and Hulsater (2005), we carried out a nondimensional analysis for $C_{\text {bed }}$ and $T_{\text {bed }}$ to better understand their relation with the local marine dynamics, sediment, and pit geometry. Based on these relationships, some general basic design recommendations for offshore sandpits are proposed in this section.

\section{Morphodynamic Nondimensional Analysis}

To illustrate the influence of the pit geometry $\left(b_{p o}\right)$, pit location $\left(h_{o}\right)$, and the local dynamics: waves $\left(H_{s o}, T_{p o}\right)$ and 
currents $\left(u_{o}\right)$ in $C_{\text {bed }}$ and $T_{\text {bed, }}$, we present Figures 10-12 Some nondimensional parameters have been defined in these figures: (1) nondimensional migration velocity: $C^{*}$ bed $=C_{\text {bed }} / C^{c} b$, where $C^{c}{ }_{b}$ is the sediment bed-load in a steady current (without waves, see definition in Appendix A); (2) the nondimensional amplitude decay time: $T^{*}{ }_{\text {bed }}=T_{\text {bed }} / T_{h o}$, where $T_{h o}$ is the time to transport $C^{c}{ }_{b}$ a horizontal distance equal to the water depth $h_{o}$ (see definition in Appendix A); (3) local ratio of surface wave height and water depth: $H_{s o} / h_{o}$, the influence of the wave period $T_{p o}$ can be included in this ratio, by means of the use of local relationships such as $T_{p o}=\alpha H_{s o}{ }^{1 / 2}$, in the case of the Balearic Islands $(\alpha=4.2)$; (4) the Froude number: $F_{r o}=u_{o} /\left(g h_{o}\right)^{1 / 2}$, which includes the influence of the flow velocity $\left(u_{o}\right)$ and water depth; (5) ratio of width of the pit and water depth: $b_{p o} / h_{o}$; and (6) migration-damping ratio $M D$ (Ribberink, 2004), amplitude decay time, and the time needed to migrate a distance similar to the pit width, $b_{p o}: M D=T_{\text {bed }} / t_{b p}$ (with $t_{b p}=b_{p o} / C_{\text {bed }}$ ). The nondimensional migration velocity $C^{*}$ bed and the nondimensional amplitude decay time $T^{*}{ }_{\text {bed }}$ are shown in Figures 10 and 11 , respectively. Regarding these figures, pits located far from the coast (deep water depths, $h_{o}=35 \mathrm{~m}$ ) are represented in figures lableled "a" and "b"; pits close to the coast (shallow water depths, $h_{o}=5 \mathrm{~m}$ ) are represented in the figures labeled "c" and "d." In a similar way, narrow pits $\left(b_{p o} / h_{o}=7.1\right)$ are represented in the figures labeled "a" and "c"; wide pits $\left(b_{p o} / h_{o}\right.$ $=71$ ) correspond to the figures labeled "b" and "d."

\section{The Nondimensional Migration Velocity $C^{*}{ }_{\text {bed }}$}

To understand the behavior of the migration velocity $C^{*}$ bed (Figure 10), we analyse two dynamic conditions: current combined with little or no wave energy and current combined with wave energy.

Current with Little or No Wave Energy $\left(H_{s o} / h_{o} \downarrow\right)$. In this case the migration velocity is the lowest. It is noted in this situation that for the same relative width $\left(b_{p o} / h_{o}\right)$, either in shallow or deep waters, the migration velocity is constant. The pit is in an unstable condition for growing tendency of $C^{*}$ bed $\uparrow$, when

- The pit is wider $\left(b_{p o} / h_{o} \uparrow\right.$ because $b_{p o} \uparrow$ and/or $\left.h_{o} \downarrow\right)$,

- The flow velocity increases $\left(u_{o} \uparrow\right)$ for wide pits $\left(b_{p o} / h_{o} \uparrow\right)$.

- The flow velocity decreases $\left(u_{o} \downarrow\right)$ for narrow pits $\left(b_{p o} / h_{o} \downarrow\right)$.

Current with Wave Energy $\left(\boldsymbol{H}_{s o} / \boldsymbol{h}_{\boldsymbol{o}} \uparrow\right)$. The migration velocity increases in an important way $\left(C^{*}\right.$ bed $\left.\uparrow\right)$ compared with only current. This aspect has been evidenced in Banyalbufar and Refeubeitx. In the case with wave energy, the migration velocity grows $\left(C^{*}\right.$ bed $\left.\uparrow\right)$ when:

- The wave height amplifies $\left(H_{s o} / h_{o} \uparrow\right)$.

- The flow velocity decreases $\left(u_{o} \downarrow\right)$.

- The pit is wider $\left(b_{p o} \uparrow\right)$.

- The pit is closer to the coast $\left(h_{o} \downarrow\right)$.

An interesting aspect to be pointed out is that the migration velocity grows when the flow velocity diminishes. In this situation, even large quantities of sediment are in suspension because of the stirring effect of the waves; the existence of a low flow velocity would transport the suspended sediment from upstream to the pit. If the pit captures a large volume of sand, the outgoing flow is not saturated with sediment in suspension; therefore, the erosion capacity is incremented at the end of the pit, in this way increasing the migration velocity.

\section{The Nondimensional Amplitude Decay Time $T^{*}{ }_{\text {bed }}$}

To understand the behavior of the amplitude decay $T^{*}$ bed (Figure 11), the same dynamic conditions analysed previously for $C^{*}$ bed are analysed in this section.

Current with Little or No Wave Energy $\left(H_{s o} / h_{o} \downarrow\right)$. In this case we have a longer amplitude decay time $\left(T^{*}\right.$ bed $\left.\uparrow\right)$, which means that the pit recuperation or damping (decay of the pit depth in time) is slower compared with the case with waves. In this case, the tendency to increase the speed for the pit recuperation ( $T^{*}$ bed $\downarrow$ ) can be obtained if:

- The flow velocity is increased $\left(u_{o} \uparrow\right)$.

- The pit is narrower $\left(b_{p o} / h_{o} \downarrow\right.$ because $b_{p o} \downarrow$ and/or $\left.h_{o} \uparrow\right)$.

It is noted that for wider pits $\left(b_{p o} / h_{o} \uparrow\right)$, some variation in flow velocities can result in important variations (some orders of magnitude) in the recuperation time of the pit.

Current with Wave Energy $\left(\boldsymbol{H}_{\text {so }} / \boldsymbol{h}_{\boldsymbol{o}} \uparrow\right)$. When the wave energy increases $\left(H_{s o} / h_{o} \uparrow\right)$, the amplitude decay time decreases in an important way $T^{*}$ bed $\downarrow$ (higher speed for the pit recuperation) compared with only current. In this case with wave energy, the speed for the pit recuperation increments (with $T^{*}{ }_{\text {bed }} \downarrow$ ) when:

- The wave height amplifies $\left(H_{s o} / h_{o} \uparrow\right)$.

- The pit is narrower $\left(b_{p o} / h_{o} \downarrow\right.$ because $b_{p o} \downarrow$ and/or $\left.h_{o} \uparrow\right)$.

- The flow velocity decreases $\left(u_{o} \downarrow\right)$.

Contrary to the situation of current without waves, it is noted that for narrower pits $\left(b_{p o} / h_{o} \downarrow\right)$, some variation in flow velocities can result in important variations (some orders of magnitude) in the recuperation time of the pit. In this case, strong currents can transport the suspended sediment downstream across the pit. This is the case of the Banyalbufar and Refeubeitx borrow areas during storm events, which are located in deep water depths, narrow pits with currents that are not too strong. Under these special conditions, the recuperation of the pits is faster. An interesting aspect to be pointed out is that for two pits, with the same nondimensional width, the same nondimensional wave height (e.g., $H_{s o} / h_{o}=$ 0.3 , see Figures 11a and c), the near-bed wave orbital flow (see Appendix A) is greater for the pit in the deepest water depth. Hence, with the same flow current, this big wave has a greater stirring effect, and the bed and suspended sediment transport will be larger. Under these conditions, the pit in the deepest water depth damps or recuperates faster than that in shallow water.

\section{The Migration-Damping Nondimensional Parameter $M D$}

The parameter $M D\left(=T_{\text {bed }} / t_{b p}\right)$, previously defined as the ratio between the amplitude decay time $T_{\text {bed }}$ and the time needed to migrate a distance similar to the pit width, $b_{p o}\left(t_{b p}\right)$ is 


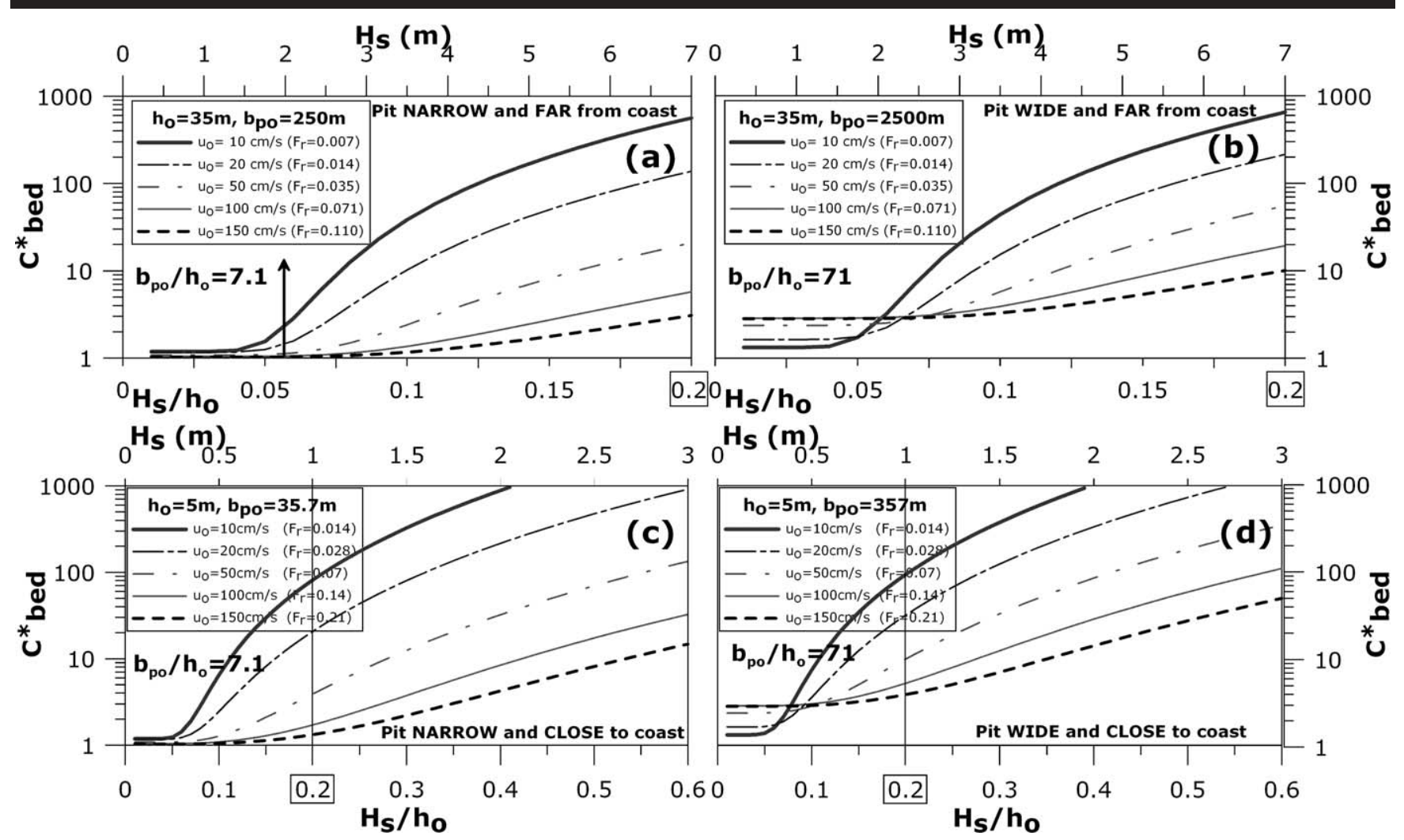

Figure 10. Nondimensional migrational velocity $\left(C^{*}{ }_{\text {bed }}\right)$ as a function of $b_{p o} / h_{o}, H_{s o} / h_{o}, F_{r o}=u_{o} /\left(g h_{o}\right)^{1 / 2}$, with calibrated sediment transport parameters (Banyalbufar).

represented in Figure 12 for two different situations: (a) as a function of $b_{p o} / h_{o}$ and Froude number $F_{r o}$, for a fixed storm wave condition $\left(H_{s o} / h_{o}=0.1\right.$ with $H_{s o}=3.5 \mathrm{~m}$ and $\left.h_{o}=35 \mathrm{~m}\right)$; and (b) as a function of $b_{p o} / h_{o}$ and $H_{s o} / h_{o}$ for a fixed mean flow velocity $\left(u_{o}=0.3 \mathrm{~m} / \mathrm{s}\right)$. In Figures $12 \mathrm{a}$ and $\mathrm{b}$, as noted for narrow pits $\left(b_{p o} / h_{o}<<1\right)$, these situations are mainly dominated by damping, even under the influence of high waves and strong currents. On the other hand, for wide pits $\left(b_{p o} / h_{o}\right.$ $>>1$ ) the dominant behaviour is migration. In this case the wave height variations do not affect this behaviour. However, flow velocity variations can change this tendency. Regarding the Refeubeitx and Banyalbufar borrow areas with narrow sandpits $\left(b_{p o} / h_{o}<8\right)$, damping dominates (see Figure 12b). However, under storm conditions, with $u_{o}<10 \mathrm{~cm} / \mathrm{s}$, migration dominates (see Figure 12a).

\section{Basic Design Recommendations}

After the application of the 1D numerical model to the Balearic sandpits, where the simple model provides good estimates of the infill ratio and migration velocity of the pits in the two borrow areas, and also based on the previous analytical solution, in the case of pits in marine environments, far from the coast with $h_{o}>20 \mathrm{~m}$, some basic design recommendations can be proposed to define the location, the orientation, and the geometry for these offshore sandpits as follows:
(1) Pit location: Once some potential borrow areas have been identified based on the required sediment characteristics, quality, and available volume, their selection mainly depends on the local dynamics (flow and waves). Associated with a location area, the water depth $\left(h_{o}\right)$ and the sediment characteristics (sediment sizes, density, etc.) are also defined.

(2) Pit orientation: As previously discussed, pit recuperation (filled) is increased if it is oriented with the principal axis $(y$-) normal to the dominant flow velocities.

(3) Pit geometry: It is defined by the pit width $\left(b_{p o}\right)$, the pit depth $\left(d_{p o}\right)$, and the pit length $\left(l_{p o}\right)$. The criterion to define $b_{p o}$ is related to the local dynamics. If the sandpit is located in a zone exposed to a dominant flow velocity with small wave energy (zone protected from waves), a narrow pit $\left(b_{p o} / h_{o}<10\right)$ is recommended because its tendency is to increase the recuperation (decreasing the migration velocity and the infill time [damping time]). In this case the sediment bottom load is the dominant process. However, if the pit is located in a zone exposed to local flow and exposed to high wave energy, the increment of the wave energy has two contrary effects in the recuperation of the pit. On one hand, waves increase the recuperation of the pit by means of holding suspension sediment, reducing the infill time. On the other hand, the pit is less stable because of the increment of the 


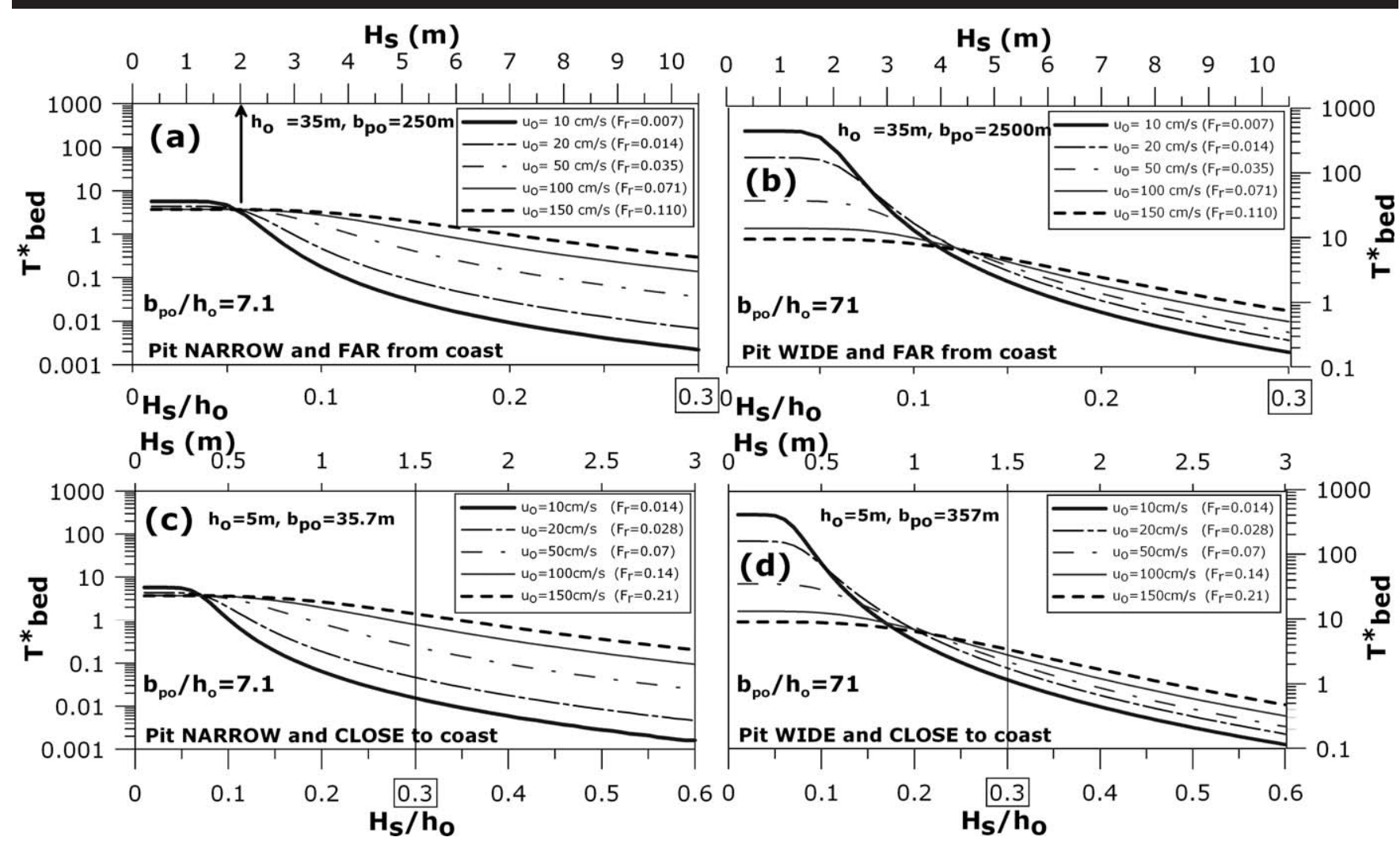

Figure 11. Nondimensional amplitude-decay time $\left(T^{*}\right.$ bed $)$ as a function of $b_{p o} / h_{o}, H_{s o} / h_{o}, F_{r o}=u_{o} /\left(g h_{o}\right)^{1 / 2}$, with calibrated sediment transport parameters (Banyalbufar).

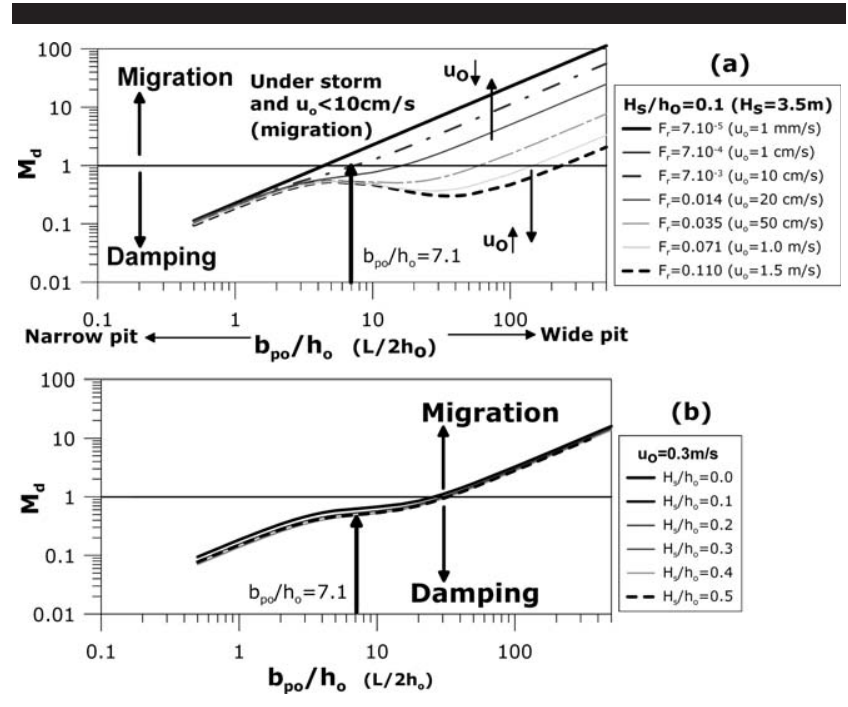

Figure 12. Migration or damping dominates, depending on the parameters $b_{p o} / h_{o}, H_{s o} / h_{o}, F_{r o}=u_{o} /\left(g h_{o}\right)^{1 / 2}$. Chezy friction parameter $\left(C=75 \mathrm{~m}^{1 / 2} / \mathrm{s}\right)$, and other sediment transport parameters obtained from the Banyalbufar calibration. migration velocity. Both behaviors are increased with the reduction of the flow velocity. The best $b_{p o}$ (to reduce both infill time and migration velocity) can be obtained by combining the local time series (flow and waves) with a simple numerical tool such as MEMPITS. Whether migration or damping, dominant trends have to be analysed combining the local time series of the dynamics, pit geometry, and bottom sediment. Regarding the pit depth $\left(d_{p o}\right)$, a small value of $d_{p o} / h_{o}<0.1$ is recommended to generate minimal disturbances in the near bottom velocity profile; it has reduced impact (morphological and biological) in the surrounding areas. In cases with deeper pits, the application of nonlinear evolution models with 3D flow approach is recommended to study pit performance. Regarding the pit length, it is recommended that $l_{p o}$ be oriented with the principal axis $(y$-) normal to the dominant flow velocities, and it is defined in the function of the required sand volume or limitations in the dimensions of the borrow area. For large pit lengths it is important to verify the morphology and dynamic uniformity along the axis $(y-)$ in the field. Finally, other recommendations regarding sandpit design can be consulted in Sandpit (2005). 


\section{CONCLUSIONS}

Based on the analytical formulation presented by Ribberink, Roos, and Hulsater (2005) and Ribberink (2004), a semianalytical numerical model (MEMPITS) has been developed to study the morphodynamic evolution of offshore $\left(h_{o}>20 \mathrm{~m}\right)$ sand borrow areas. This semianalytical tool allows a quick systematic investigation of the physical mechanisms as well as a detailed sensibility analysis regarding the pit design parameters.

The model has been applied to study the morphodynamic evolution of two offshore sand borrow areas in the Balearic Islands (Spain) where field data allowed a detailed characterization of the evolution of the sandpits. The simple 1D model provides, with a fine tuning of calibration factors, good estimates of the infill ratio and migration velocity in the offshore Balearic pits. The quantitative and qualitative behavior obtained with the 1D morphodynamic model agrees with results obtained from earlier studies assuming depth-averaged flow.

The pit evolution has been expressed in terms of pit indicators: the migration velocity $C_{\text {bed }}$ and the amplitude decay time $T_{\text {bed }}$ govern the morphodynamic evolution of pits and involve the most important process to define their migration and the infill time (damping time). A nondimensional analysis has been carried out for $C_{\text {bed }}$ and $T_{\text {bed }}$ to better understand their relation to the local marine dynamics, sediment, and pit geometry. One of the most important conclusions of this sensitivity analysis is that wave energy plays a relevant role in pit evolution. It has two contrary effects in the recuperation of the pit. On one hand, big energy waves have a greater stirring effect, and the bed and suspended sediment transport will be larger, allowing the pit to increase the capacity to hold sediment, reducing the infill time. On the other hand, the pit is less stable because of the increase of migration velocity. Both behaviors are increased with reduction of flow velocity. Whether migration or damping is the dominant process, it has to be analysed combining the local time series of the dynamics, pit geometry, and bottom sediment.

The Refeubeitx borrow area, which is located in a shallower water depth $\left(h_{o}=20 \mathrm{~m}<35 \mathrm{~m}\right)$, and is characterized by a larger bottom sediment size $\left(D_{50}=0.35 \mathrm{~mm}\right)$, a wider pit $\left(b_{p o} /\right.$ $\left.h_{o}=8\right)$, and is protected from important wave storms and currents, has a slower migration velocity $\left(C_{b e d}\right)$ and a longer amplitude-decay time ( $\left.T_{\text {bed }}\right)$ than Banyalbufar. This means that the pit in Refeubeitx requires a longer period to recuperate (decay of the pit depth in time).

These analytical formulations, based on many hypotheses, constitute a practical and easy-to-use design engineering tool. Furthermore, these kinds of models combined with hindcast and forecast of local dynamic data sets can be applied to predesign pits (geometry, orientation, and location) located offshore and to predict their morphological evolution

\section{ACKNOWLEDGMENTS}

The authors gratefully acknowledge the financial support provided by the Conselleria de Medi Ambient Govern de les Illes Balears. M. González is indebted to the Spanish Ministerio de Educación y Ciencia under the Program for mobility of professors in foreign centres for its support. The authors express their gratitude to the Spanish Holding of Harbors (Puertos del Estado) for providing offshore wave and wind data series.

\section{LITERATURE CITED}

Bailard, J.A., 1981. An energetics total load sediment transport model for a plane sloping beach. Journal of Geophysical Research, 86, 10938-10964.

Basco, D.R., 1999. A Methodology and Criteria to Assess the Impacts of Sand Volume Removed in Federal Waters on the Nearshore Wave Climate. Norfolk, VA: Coastal Engineering Center, Old Dominion University.

Basco, D.R. and Lonza, F.R., 1997. Nearshore wave transformation altered by sand volumes removed from borrow areas for beach nourishment. In: Proceedings of the 3rd International Symposium on Ocean Wave Measurement and Analysis (New York, ASCE), pp. 37-48.

Bender, C.J., 2001. Wave Field Modifications and Shoreline Response Due to Offshore Borrow Areas. Gainesville, Florida: University of Florida, Master's thesis, XXp.

Benedet, L. and List, J.H., 2008. Evaluation of the physical process controlling beach changes adjacent to nearshore dredge pits. Coastal Engineering, 55, 1224-1236.

Boers, M., 2005. Overview of Historical Pits, Trenches in Dump Sites of the NCS. SANDPIT, Sand Transport and Morphology of Offshore Sand Mining Pits. Final Report. Brussels, Belgium: European Union Commission.EC Framework V Project. No. EVK3-200100056, pp. H1-H9.

Chesher, T.J.; Soulsby, R.L., and Foley, W.J., 2005. Scenario Testing Approach and Results for Sand Mining Pits. SANDPIT, Sand Transport and Morphology of Offshore Sand Mining Pits. Final report. Brussels, Belgium: European Union Commission. EC Framework V Project. No. EVK3-2001-00056, pp. I1-I14.

Chesher, T.J.; Soulsby, R.L.; Foley, W.J.; Sterlini, P.E., and Jervis, G., 2005. Morphological Modelling Using the 2DH Model, PISCES SANDPIT, Sand Transport and Morphology of Offshore Sand Mining Pits. Final report. Brussels, Belgium: European Union Commission.EC Framework V Project. No. EVK3-2001-00056, pp. A0-1-A0-12.

Conselleria de Medi Ambient Balears, 2006. Estudio del tiempo de recuperación de las zonas de préstamo de sedimento marinos en las Illes Balears. Final report. Palma de Majorca, Spain: Conselleria de Medi Ambient Balears [in Spanish]. 240p.

Davies, A.G.; Van Rijn, L.C.; Damgaard, J.S.; Van de Graaff, J., and Ribberink, J.S., 2002. Intercomparison of research and practical sand transport models. Coastal Engineering, 46 (1), 1-23.

Davies, A.G.; Berx, B.E.; Brown, J.M., and Villaset, C., 2005. SANDPIT, Sand Transport and Morphology of Offshore Sand Mining Pits. Brussels, Belgium: European Union Commission. Final Report. EC Framework V Project. No. EVK3-2001-00056, pp. AS1-AS14.

De Groot, P.J., 2004. Modeling the Morphological Behaviour of Sandpits. Influence Sediment Transport Formula and Verification of a 1DH Model. Enschede, The Netherlands: University of Twente, Master's thesis, civil engineering. 110p.

Demir, H.; Otay, E.N.; Work, P.A., and Börekci, O.S., 2004. Impacts of dredging on shoreline change. Journal of Waterway, Port, Coastal and Ocean Engineering, 130(4), 170-178.

Demirov, E. and Pinardi, M., 2002. The simulation of the Mediterranean Sea circulation from 1979 to 1993. Part I: the interannual variability. Journal of Marine Systems, 33-34, 23-50.

Dietrich, D.E., 1997. Application of a modified "a" grid ocean model having reduced numerical dispersion to the Gulf of Mexico circulation. Dynamic Atmosphere and Oceans, 27, 201-217.

Dietrich, D.E.; Haney, R.L.; Fernandez, V.; Josey, S., and Tintore, J., 2004. Air-sea fluxes based on observed annual cycle surface climatology and ocean model internal dynamics: a precise, nondamping zero-phase-lag approach applied to the Mediterranean Sea. Journal of Marine Systems, 52, 145-165.

Dietrich, D.E.; Marietta, M.G., and Roache, P.J., 1987. An ocean modeling system with turbulent boundary layers and topography, 
part 1: numerical description. International Journal of Numerical Methods in Fluids, 7, 833-855.

EPPE (Ente Público Puertos del Estado), 2003. Reanálisis de 44 años (1958-2001) del clima oceánico y atmosférico en el Mar Mediterráneo: Informe Técnico de la contribución de Puertos del Estado al proyecto europeo HIPOCAS. Brussels, Belgium: European Union Commisson. 30p. [in Spanish].

EUROSION, 2004. Living with Coastal Erosion in Europe: Sediment and Space for Sustainability, Part I-Major Findings and Policy Recommendations of the EUROSION Project. Report in the framework of EUROSION Project. Brussels, Belgium: Directorate General Environment, European Commission, EU.

Fernández, V., 2004. Numerical Studies of the Mediterranean Sea Variability. Palma de Majorca, Spain: Universidad de las islas Baleares. Ph.D. thesis.

Font, J.; Salat, J., and Tintoré, J., 1988. Permanent features of the circulation in the Catalan Sea. Oceanologica Acta, S-9, 51-57.

Galappatti, R. and Vreugdenhil, C.B., 1985. A depth-integrated model for suspended transport. Journal of Hydrology, 23(4), 359-377.

GIOC (Grupo de Ingeniería Oceanográfica y de Costas), 2003. Modelo de Propagación de Oleaje Espectral (Oluca-SP 2.0). Manual de Referencia, Modelo de Ayuda a la Gestión del Litoral Español Edición. Santander, Spain: Universidad de Cantabria-Ministerio de Medio Ambiente, 170p. [in Spanish].

Gómez, M. and Carretero, J.C., 1997. A two-way nesting procedure for the WAM model: application to the Spanish coast. Journal of Offshore Mechanics and Arctic Engineering, 119(1), 20-24.

González, M.; Medina R; González-Ondina, J.; Osorio, A.; Méndez, F.J., and García, E., 2007. An integrated coastal modeling system for analyzing beach processes and beach restoration projects, SMC. Computers \& Geosciences (Elsevier), 33(7), 916-931.

Günther, H.; Hasselmann, S., and Janssen, P.A.E.M.,1991. Wamodel Cycle 4. Technical Report No.4, Germany: Deutsches Klima Rechen Zentrum. 102p.

Günther, H.; Lionello, P.; Janssen, P.A.E.M.; Bertotti, L.; Brüning, C.; Carretero, J.C.; Cavaleri, L.; Guillaume, A.; Hansen, B.; Hasselmann, S.; Hasselmann, K.; de las Heras, M.; Hollingsworth, A. Holt, M.; Lefevre, J.M., and Portz, R., 1992. Implementation of a Third Generation Ocean Wave Model at the European Centre for Medium Range Weather Forecasts. ECMWF. Technical Report No. 68, Reading, UK: European Centre for Medium Range weather Forecasts (ECMWF).

Havinga, F.J., 1992. Sediment Concentrations and Sediment Transport in Case of Irregular Non-Breaking Waves with a Current. Delft Hydraulics Report H840, Delft, The Netherlands: Delft Hydraulics.

Hjelmager, J. and Zyserman, J., 2005. Flow and Sediment Transport over Sand Pits of Varying Geometry. Final Report. EC Framework V Project. No. EVK3-2001-00056. Brussels, Belgium: European Union Commission. pp. AR1-AR10.

Horikawa, K.; Sasaki, T., and Sakuramoto, H., 1977. Mathematical and laboratory models of shoreline changes due to dredged holes. Journal of the Faculty of Engineering, University of Tokyo, 34(B), 49-57.

Johnsson, I.G., 1980. A new approach to oscillatory, rough, turbulent boundary layers. Ocean Engineering, 7, 109-152.

Kelley, S.W.; Ramsey, J.S., and Byrnes, M.R., 2004. Evaluating the physical effects of offshore sand mining for beach nourishment. Journal of Coastal Research, 20(1), 89-100.

Kirby, J.T. and Dalrymple, R.A. 1992. Combined Refraction/Diffraction Model REF/DIF 1, Version 2.4.; Documentation and User's Manual, Research Report CACR-92-04. Newark, Delaware: Center for Applied Coastal Research, University of Delaware.

Kirby, J.T. and Özkan H.T., 1994. Combined Refraction/Diffraction Model for Spectral Wave Conditions. Ref/Dif s version 1.1. Documentation and User's Manual, Report No. CACR-94-04. Newark, Delaware: Center for Applied Coastal Research, University of Delaware.

Pacanowski, R.C. and Philander, S.G.H., 1981. Parameterization of vertical mixing in numerical models of tropical oceans. Journal of Physical Oceanography, 30, 1069-1082.

Ribberink, J.S., 1989. Zeezandwinning. Onderbouwend rapport: milieu effect rapportage RON, discussienota kustverdediging,
Technisch Rapport 10, Report H825. Delft, The Netherlands: WL/ Delft Hydraulics, [in Dutch].

Ribberink, J.S.; Roos, P.C., and Hulsater, S., 2005. Morphodynamics of trenches and pits under the influence of currents and wavessimple engineering formulas. In: Proceedings of Coastal Dynamic '05. (Barcelona, ASCE). 14p.

Ribberink, T.S., 2004. Migration and in fills of trenches in the marine environment: an analytical engineering model. Report EU Project Sand Pit. Twente, The Netherlands: University of Twente. 68p.

Roos, P.C., 2004. Seabed Pattern Dynamics and Offshore Sand Extraction. Twente, The Netherlands: University of Twente, $\mathrm{Ph}$ D. thesis, ISBN 90-365-2067-3

Roos, P.C.; Hulscher, S.J.M.H., and de Vriend, H.J., 2008. Modelling the morphodynamic impact of offshore sandpit geometries. Coastal Engineering, 55, 704-715.

SANDPIT, 2005. Sand Transport and Morphology of Offshore Sand Mine Pits. EU Project EVK3-2001-00056. Blokzijl, The Netherlands: Aqua Publications. 600p.

Simons, R. and Hollingham, S., 2001. Marine Aggregate Dredging: A Review of Current Procedures for Assessing Coastal Processes and Impact at the Coastline. Technical Report. HYD10401, London, UK: Civil and Environmental Engineering Department, University College of London.

Staneva, J.; Dietrich, D.; Stanev E., and Bowman, M., 2001. Rim current and coastal eddy mechanisms in an eddy-resolving Black Sea general circulation model. Journal of Marine Systems, Special Issue on the Black Sea, 31, 137-157.

Svasck, J.N., 1965. Behaviour of a trial dredged trench in the sea bed of the North Sea near Scheveningen. Report K-272. The Hague, The Netherlands: Rijkswaterstaat Deltadienst [in Dutch].

Swart, D.H., 1976. Predictive equations regarding coastal transports. Proceedings of the 15th International Conference on Coasta Engineering, Honolulu, American Society of Civil Engineers, pp. 1113-1132.

Tomás, A.; Méndez, F.J., and Losada, I.J., 2008. A method for spatial calibration of wave reanalysis data bases, Continental Shelf Research, 28, 391-398. doi:10.1016/j.csr.2007.09.009.

Van Alphen, S.L.J.; van Hallie, F.P.; Ribberink, J.S.; Roelvink, J.A., and Loisse, C.J., 1990. Offshore sand extraction and nearshore profile nourishment. In: Proceedings of the 22nd Coastal Engineering Conference, ICCE (Delft, The Netherlands, ASCE), Volume 2 , pp. 1998-2009.

Van Rijn, L.C., 1986. Sedimentation of dredged channels by currents and waves. Journal of Waterway, Port, Coastal and Ocean Engineering ASCE, 112(5), 318-340.

Van Rijn, L.C., 2005a. State of the art review: process and prediction models. Brussels, Belgium: European Union Commission. SANDPIT Fifth Framework Project. No. FVK3-CT-2001-00056.

Van Rijn, L.C., 2005b. Principles of Sedimentation and Erosion Engineering in Rivers, Estuaries and Coastal Seas. Location, Netherlands: Aqua Publications.

Van Rijn, L.C.; Walstra, D.J.R., and Ormand T.M, 2004. Description of Transport 2004 and Implementation in Delft-3D-Online. Delft Hydraulics Report Z3748. Delft, The Netherlands: Delft Hydraulics.

Walstra, D.J.R.; Van Rijn, L.C., and De Boer, G., 2002. Morphology of Pits, Channels and Trenches. Part II: Model Verification of Delft3D with PUTMOR Dataset. Report Z3223.25, Delft, The Netherlands: WL | Delft Hydraulics.

WAMDI Group: Hasselmann, S.; Hasselmann, K.; Bauer, E.; Janssen, P.A.E.M.; Komen, G.J.; Bertotti, L.; Lionello, P.; Guillaume, A.; Cardone, V.C.; Greenwood, J.A.; Reistad, M.; Zambresky, L., and Ewing, J.A., 1988. The WAM model-a third generation ocean wave prediction model. Journal of Physical Oceanography, 18, 17751810 .

Werner, F.E.: Viúdez, A., and Tintoré, J., 1993. An exploratory numerical study of the currents off the southern coast of Mallorca including the Cabrera Island complex. Journal of Marine Systems, 4, 45-66.

Work, P.; Fehrenbacher, F. and Voulgaris, G., 2004. Nearshore impacts of dredging for beach nourishment, Journal of Waterway, Port, Coastal and Ocean Engineering, 130 (6), 303-311. 


\section{APPENDIX A: MIGRATION VELOCITY $C_{\text {bed }}$ AND AMPLITUDE DECAY TIME $\boldsymbol{T}_{\text {bed }}$}

Detailed description of these relationships can be consulted in Ribberink (2004) and Ribberink, Roos, and Hulsater (2005).

$$
\begin{aligned}
& C_{\text {bed }}=\frac{1}{\left(1-\varepsilon_{o}\right) h_{o}}\left[3 q_{b o}^{c}+q_{b o}^{w c}(1+2 f)+\frac{4 q_{s o}^{c}+2 q_{s o}^{w c}(1+f)}{L_{A}^{2} k^{2}+1}\right] \text { current-dominant, } \\
& C_{\text {bed }}=\frac{1}{\left(1-\varepsilon_{o}\right) h_{o}}\left[3 q_{b o}^{c}+q_{b o}^{w c}(1+2 f)+\frac{q_{s o}^{w}(1+3 f)+\alpha_{s} q_{s o}^{c w}(3+f)}{L_{A}^{2} k^{2}+1}\right] \text { wave-dominant, } \\
& T_{\text {bed }}=\left(1-\varepsilon_{o}\right) h_{o}\left[L_{A} k^{2} \frac{4 q_{s o}^{c}+2 q_{s o}^{w c}(1+f)}{L_{A}^{2} k^{2}+1}+\frac{k^{2} h_{o}}{\tan \varphi}\left(\left|q_{b o}^{c}\right|+\frac{3}{2}\left|q_{b o}^{w c}\right|\right)\right]^{-1} \text { current-dominant, } \\
& T_{\text {bed }}=\left(1-\varepsilon_{o}\right) h_{o}\left[L_{A} k^{2} \frac{q_{s o}^{w}(1+3 f)+\alpha_{s} q_{s o}^{w c}(3+f)}{L_{A}^{2} k^{2}+1}+\frac{k^{2} h_{o}}{\tan \varphi}\left(q_{b o}^{w}+\frac{3}{2}\left|q_{b o}^{c w}\right|\right)\right]^{-1} \text { wave-dominant, }
\end{aligned}
$$

where the dominant condition is a relationship between the near-bed wave orbital flow and the near-bed current:

Wave dominant condition: $u_{b o}<\hat{U}_{o}$ or $\left[u_{o}<\frac{\alpha_{b} \pi H_{s o}}{T_{p o} \sin h\left(k_{w o} h_{o}\right)}\right]$

Current dominant condition: $u_{b o}>\hat{U}_{o}$ or $\left[u_{o}>\frac{\alpha_{b} \pi H_{s o}}{T_{p o} \sin h\left(k_{w o} h_{o}\right)}\right]$

$\hat{U}_{o}=\pi \frac{H_{s o}}{T_{p o}} \frac{1}{\sinh \left(k_{w o} h_{o}\right)}$ (near-bed wave orbital flow)

$u_{b o}=\alpha_{b} u_{o}$ (near-bed flow velocity with $u_{0}$ as the water depth-averaged current velocity)

$q_{b o}^{c}=m_{b} \alpha_{b}^{3} u_{o}^{3}$

$q_{b o}^{w c}=\frac{1}{2} m_{b} \alpha_{b} \hat{U}_{o}^{2} u_{o}$ (bed-load transport: current ${ }^{\mathrm{c}}$ and wave ${ }^{\mathrm{w}}$ contributions)

$f=\frac{k_{w \infty} h_{o} \sin h\left(2 k_{w o} h_{o}\right)}{2 k_{w o} h_{o}+\sin h\left(2 k_{w o} h_{o}\right) \tan h^{2}\left(k_{w o} h_{o}\right)}$ (parameters associated with surface waves)

$q_{s o}^{c}=m_{s} \alpha_{s}^{4} u_{o}^{4} \frac{q}{|q|} \quad q=u_{o} \cdot h_{o}$ (current-dominant)

$q_{s o}^{w c}=\frac{3}{4} m_{s} \alpha_{s}^{2} \hat{U}_{o}^{2} u_{o}^{2} \frac{q}{|q|}$ (suspended-load: current ${ }^{\mathrm{c}}$ and wave ${ }^{\mathrm{w}}$ contributions)

$q_{s o}^{w}=m_{s} \frac{4}{3 \pi} \hat{U}_{o}^{3} \alpha_{s} u_{o}$ (wave-dominant)

$q_{s o}^{c w}=\frac{3}{\pi} m_{s} \alpha_{s}^{2} \hat{U}_{o} u_{o}^{3}$

$q_{b o}^{w}=m_{b} \frac{4}{3 \pi} \hat{U}_{o}^{3}$ (wave-dominant)

$q_{b o}^{c w}=\frac{2}{\pi} m_{b} \alpha_{b}^{2} \hat{U}_{o} u_{o}^{2}$

$D_{i b}=\frac{\left|q_{b o}^{c}\right|+\frac{3}{2}\left|q_{b o}^{w c}\right|}{\left(1-\varepsilon_{o}\right) \tan \varphi}$ (current-dominant) 


$$
\begin{aligned}
& D_{i b}=\frac{q_{b o}^{w}+\frac{3}{2} q_{b o}^{w c}}{\left(1-\varepsilon_{o}\right) \tan \varphi} \text { (wave-dominant) } \\
& D_{i s}=0 \text { (wave- and current- dominant) } \\
& L_{A}=\widetilde{L} \frac{u_{o} h_{o}}{w_{s}}(\text { suspended sediment adjustment length) } \\
& C_{b}^{c}=\frac{3 q_{b o}^{c}}{\left(1-\varepsilon_{o}\right) h_{o}}(\text { sediment bed-load in a steady current, no waves) } \\
& T_{h o}=\frac{h_{o}}{C_{b}{ }^{c}}\left(\text { time to transport } C_{b}^{c} \text { a horizontal distance equal to } h_{o}\right) \\
& k=\frac{2 \pi}{L}=\frac{2 \pi}{2 b_{p o}}\left(L=\text { bed wavelength, } b_{p o}=\text { pit width, see Figure } 7\right) \\
& m_{b}=\frac{C_{f} \varepsilon_{b}}{\Delta g \text { tan } \varphi} ; \quad m_{s}=\frac{\varepsilon_{s} C_{f}}{\Delta g w_{s}} ; \quad \varepsilon_{b}=0,1 ; \quad \varepsilon_{s}=0,02 \text { (Bailard coefficients) } \\
& C_{f}=0.5 f_{w}\left(f_{w}:\right. \text { wave friction coefficient [Swart, 1976; Johnsson, 1980]) }
\end{aligned}
$$

A discussion about the application of this coefficient is presented in De Groot (2005). $\varepsilon_{o}=$ porosity $(=0.4), \phi=$ angle of repose ( standard value $=32^{\circ}$ ), $\alpha_{s}, \alpha_{b}, \hat{L}=$ velocity and concentration profile coefficients (standard value $=0.5$ ), $K_{w o}=$ local wave number of waves (undisturbed bed zones not affected by the pit), $K_{w_{\infty}}=$ wave number in deep waters. $\Delta=$ relative density of sediment, $w_{s}$ $=$ settling velocity of sediment.

\section{Notation}

a initial sandpit amplitude

$b_{p o} \quad$ mean width of the pit

$C \quad$ advection velocity of the seabed $\left(c_{b}+c_{s}\right)$

$c_{b} \quad$ migration velocity due to bed-load

$C_{\text {bed }} \quad$ migration velocity of the sandpit

$C^{c}{ }_{b} \quad$ sediment bed-load in a steady current without waves

$C^{*}$ bed nondimensional migration velocity

$C_{f} \quad$ friction coeficient

$c_{s} \quad$ migration velocity due to suspended-load

$D \quad$ diffusion coefficient $\left(L_{A} c_{b}+D_{i b}\right)$

$D_{50} \quad$ median grain size

$D_{90} \quad$ grain size such that $90 \%$ of the material in the sample is finer

$D_{i b} \quad$ diffusion coefficient due to bed-slope effect

$d_{p o} \quad$ mean dredged pit depth

$F_{r o} \quad$ Froude number $\left[F_{r o}=u_{o} /\left(g h_{o}\right)^{0.5}\right]$

$f_{w} \quad$ wave friction coefficient

$g \quad$ acceleration of gravity

$h_{o} \quad$ mean water depth in borrow area

$H_{s} \quad$ significant wave height

$H_{s o} \quad$ significant wave height in borrow area

$k \quad$ bottom wave number of the pit $(=2 \pi / L)$

$K_{w o} \quad$ wave number of waves in borrow area

$K_{w \infty} \quad$ wave number of waves in deep waters

$L \quad$ bottom wavelength of the pit

$\hat{L} \quad$ concentration profile coefficient

$L_{A} \quad$ adjustment length for suspended sediment

$l_{p o} \quad$ mean length of the pit in $y$ -

$M D$ migration-damping ratio 


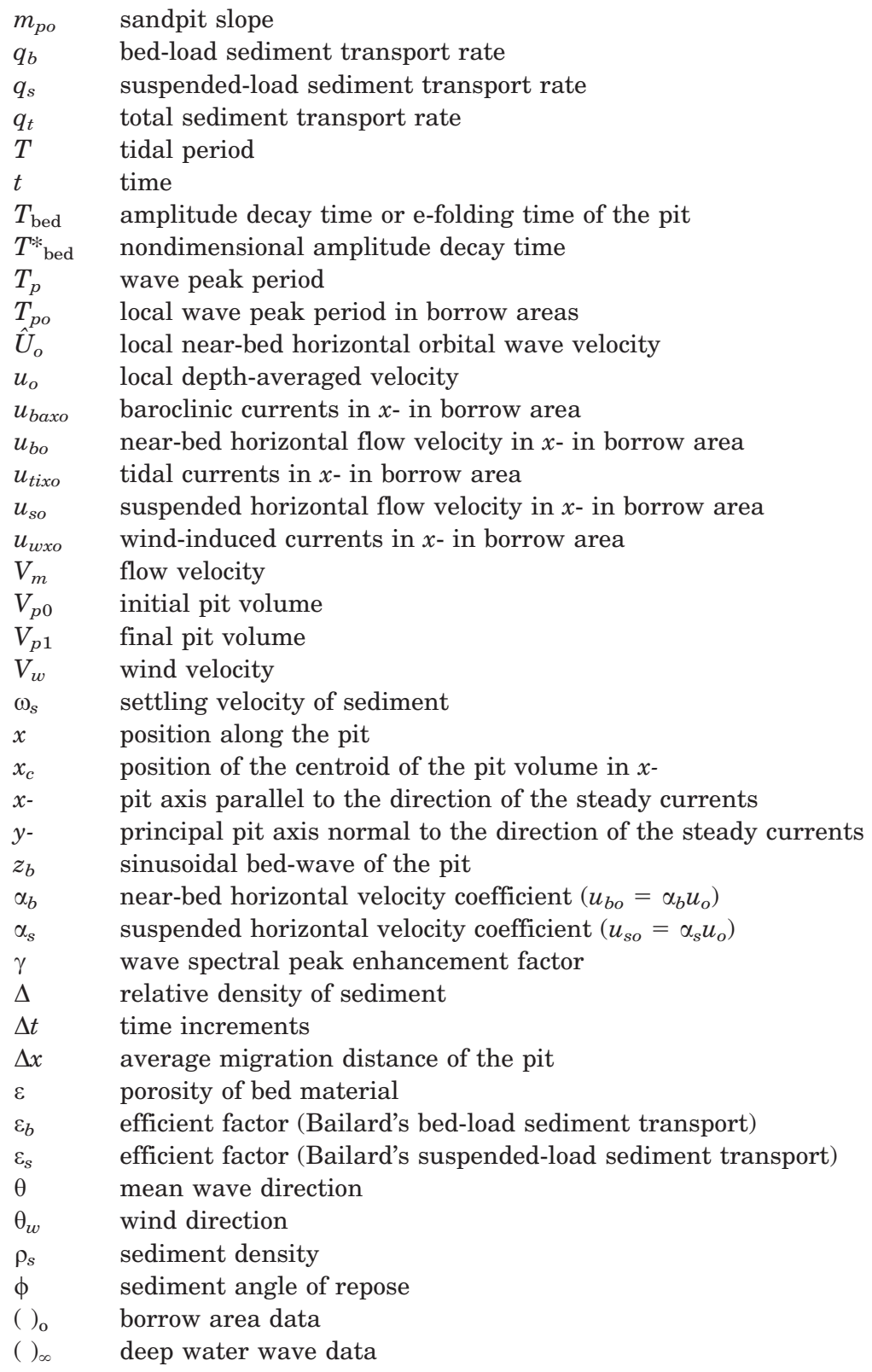

